\title{
Deployable Aeroshell Flexible Thermal Protection System Testing
}

\author{
Stephen J. Hughes ${ }^{1}$ \\ NASA Langley Research Center, Hampton, VA, 23681 \\ Joanne S. Ware ${ }^{2}$ \\ ILC Dover, Frederica, DE, 19946 \\ Joseph A. Del Corso ${ }^{3}$ \\ NASA Langley Research Center, Hampton, VA, 23681 \\ and \\ Rafael A. Lugo ${ }^{4}$ \\ National Institute of Aerospace, Hampton VA, 23666
}

\begin{abstract}
Deployable aeroshells offer the promise of achieving larger aeroshell surface areas for entry vehicles than otherwise attainable without deployment. With the larger surface area comes the ability to decelerate high-mass entry vehicles at relatively low ballistic coefficients. However, for an aeroshell to perform even at the low ballistic coefficients attainable with deployable aeroshells, a flexible thermal protection system (TPS) is required that is capable of surviving reasonably high heat flux and durable enough to survive the rigors of construction handling, high density packing, deployment, aerodynamic loading and aerothermal heating. The Program for the Advancement of Inflatable Decelerators for Atmospheric Entry (PAIDAE) is tasked with developing the technologies required to increase the technology readiness level (TRL) of inflatable deployable aeroshells, and one of several of the technologies PAIDAE is developing for use on inflatable aeroshells is flexible TPS. Several flexible TPS layups were designed, based on commercially available materials, and tested in NASA Langley Research Center's 8 Foot High Temperature Tunnel (8ft HTT). The TPS layups were designed for, and tested at three different conditions that are representative of conditions seen in entry simulation analyses of inflatable aeroshell concepts. Two conditions were produced in a single run with a sting-mounted dual wedge test fixture. The dual wedge test fixture had one row of sample mounting locations (forward) at about half the running length of the top surface of the wedge. At about two thirds of the running length of the wedge, a second test surface drafted up at five degrees relative to the first test surface established the remaining running length of the wedge test fixture. A second row of sample mounting locations (aft) was positioned in the middle of the running length of the second test surface. Once the desired flow conditions were established in the test section the dual wedge test fixture, oriented at 5 degrees angle of attack "down," was injected into the flow. In this configuration the aft sample mounting location was subjected to roughly twice the heat flux and surface pressure of the forward mounting location. The tunnel was run at two different conditions for the test series: 1) "Low Pressure", and 2) "High Pressure". At "Low Pressure" conditions the TPS layups were tested at $6 \mathrm{~W} / \mathrm{cm}^{2}$ and $11 \mathrm{~W} / \mathrm{cm}^{2}$ while at "High Pressure" conditions the TPS layups were tested at $11 \mathrm{~W} / \mathrm{cm}^{2}$ and $20 \mathrm{~W} / \mathrm{cm}^{2}$. This paper details the test configuration of the TPS
\end{abstract}

\footnotetext{
${ }^{1}$ PAIDAE Lead Engineer, Mechanical Systems Branch, NASA LaRC/MS 432, AIAA Member.

${ }^{2}$ PAIDAE Materials Lead, Materials Development Group, ILC DoverLP, 1 Moonwalker Rd, Frederica DE.

${ }^{3}$ PAIDAE Thermal Engineer, SED/Structures and Thermal Systems Branch, NASA LaRC/MS 432, AIAA Member.

${ }^{4}$ PAIDAE Engineer, National Institute of Aerospace, LaRC/MS 431, and AIAA Member.
} 
samples in the 8Ft HTT, the sample holder assembly, TPS sample layup construction, sample instrumentation, results from this testing, as well as lessons learned.

\section{Nomenclature}

$\begin{array}{ll}\circ & =\text { degrees } \\ \text { 8Ft HTT } & =8 \text { Foot High Temperature Tunnel } \\ \text { AIRS } & =\text { Aeroassist Inflatable Reentry Systems } \\ \text { AoA } & =\text { Angle of Attack } \\ \mathrm{C} & =\text { centigrade } \\ \mathrm{CFD} & =\text { Computational Fluid Dynamics } \\ \mathrm{cm} & =\text { centimeters } \\ \mathrm{ft} & =\text { foot } \\ \mathrm{HMMS} & =\text { High Mass Mars System } \\ \text { in } & =\text { inch } \\ I R V E & =\text { Inflatable Reentry Vehicle Experiment } \\ \mathrm{kPa} & =\text { kilo Pascal } \\ \mathrm{LaRC} & =\text { Langley Research Center } \\ P A I D A E & =\text { Program for the Advancement of Inflatable Decelerators for Atmospheric Entry } \\ \mathrm{SiO} O_{2} & =\text { Silicone Dioxide } \\ T P S & =\text { Thermal Protection System } \\ W & =\text { Watts } \\ h & =\text { height } \\ \mathrm{i} & =\text { time index during navigation } \\ j & =\text { waypoint index }\end{array}$

\section{Introduction}

DPLOYABLE aeroshells are currently being proposed as one potential means of increasing landed payload capability for High Mass Mars Systems (HMMS). Deploying the aeroshell can produce significantly lower ballistic coefficients than those achievable with rigid aeroshells that fit within the launch vehicle shroud, and lower ballistic coefficients can allow the delivery of more payload mass to the surface for equivalent trajectory constraints. Lower ballistic coefficients also produce lower entry heating for equivalent entry conditions. However, even with the significantly lower ballistic coefficients achievable with the deployable aeroshell, there is still appreciable aerodynamic heating on entry requiring a flexible Thermal Protection System (TPS). The flexible TPS must be capable not only of sustaining the aerothermal loading of hypersonic entry, but also be durable enough to survive the mechanical loading applied during manufacturing, high density packing, rapid deployment, and aerodynamic loading. One type of deployable aeroshell is the Inflatable Aerodynamic Decelerator (IAD). An IAD is comprised of three main component sets: the inflatable structure, consisting of some type of bladder or collection of bladders, the mechanical attachment of the bladder to the payload to be decelerated, and a TPS to protect some or all of the IAD components from aerodynamic heating.

\section{Background of the PAIDAE testing}

The Program for the Advancement of Inflatable Decelerators for Atmospheric Entry (PAIDAE) is responsible for developing the technologies required to make IAD's capable of meeting HMMS requirements. One of these required technologies is a flexible TPS. PAIDAE studies are currently focused on utilizing "off the shelf” materials capable of surviving relevant peak entry heating, on the order of 5 to $30 \mathrm{~W} / \mathrm{cm}^{2}$, in combination with relevant surface pressures, on the order of $2 \mathrm{kPa}$, while limiting the back face temperatures to a $250^{\circ} \mathrm{C}$ range, which is a reasonable peak temperature for a Silicone coated Kevlar bladder. These values for peak flux and bladder temperature were determined from several entry simulation studies for previous projects and material strength testing at temperature for the Inflatable Reentry Vehicle Experiment (IRVE). Ongoing materials studies in the PAIDAE program are currently attempting to improve, among other things, the peak bladder temperature capability.

NASA Langley Research Center (LaRC) has resumed study of the application of inflatable aeroshells for the past five years with projects that include IRVE, Aeroassist Inflatable Reentry System (AIRS) and PAIDAE. Throughout these projects LaRC personnel have matured the analysis tools for trajectory simulation, aerothermal heating, structural and thermal analysis peculiar to flexible inflatable aeroshell development. 
The 8 Foot High Temperature Tunnel (8Ft HTT) is a combustion heated, hypersonic blowdown wind tunnel at LaRC capable of producing the thermal fluxes desired for PAIDAE testing. As the name implies, the open jet test section is eight feet in diameter, and the test section is $12 \mathrm{ft}$ in length. The High Energy test medium is the combustion byproducts of methane and air. An array of nozzles produces Mach numbers of four, five and seven in the test section ${ }^{1}$. Free stream pressure can match a range of altitude from 50,000 to 120,000ft. The facility has a wedge shaped test article, or "sled," used in the past for TPS testing. Minor modifications of the sled were required to meet the PAIDAE testing needs. The sled is mounted to a sting that allows for pitching up and down in the test section. The sting rides on an elevator that retracts the sled from the test section for tunnel start up and injects the model into the test section once the desired flow conditions have been established.

Experienced with the design and manufacturing of highly engineered inflatable softgoods, such as the Mars Landing Impact Airbags, IRVE, and the PAIDAE 10x10 Wind Tunnel Articles, ILC Dover was ILC Dover is the soft goods manufacturing company that was tasked with the construction of the IRVE inflatable aeroshell, so they were already familiar with construction of a deployable aeroshell. They were contracted by PAIDAE to produce the TPS test coupons for the aerothermal testing.

Three material categories were deemed necessary for the TPS layup: A durable high temperature capable outer fabric layer required to encapsulate and protect the underlying layers, an insulating layer required to reduce the high temperature of the outer surface to a temperature that the inflatable bladder can tolerate, and, a gas barrier layer required to prevent the relatively high surface pressure hot gasses on the forward surface of the aeroshell from being drawn through the layup by the low pressure in the wake of the aeroshell. Many candidates from many different manufacturers were considered for each of the categories. Several candidates looked promising on paper, but when actually in hand were found to be unworkable because they were far too delicate to survive the rigors of construction, packing, deployment or aerodynamic loading. Thermophysical properties for some candidate materials were also not provided in manufacturer documentation, and difficult to determine. For example emissivity of the outer fabric is important for computation of the radiant energy to the environment. Most of the manufacturers list emissivity at room temperature, but fail to report temperature dependent properties. NASA test data for one of the candidate materials indicated that emissivity is highly temperature dependent at the temperatures predicted on the outer aeroshell surface, emphasizing the need for better resolution of the thermophysical properties. Environmental considerations and their impact on thermophysical properties also underscored the need for better properties. For example thermal conductivity of the insulators was most often only provided at sea level static pressure, but the inflatable deployable aeroshells will be operated at an ambient pressure near vacuum, which would result in a much lower ply thermal conductivity. Experience of the PAIDAE team garnered from the preceding inflatable deployable aeroshell projects allowed reasonable estimation of material properties for materials with gaps in their properties data.

\section{Background of the PAIDAE testing}

The 8Ft HTT has a sting-mounted, wedge-shaped fixture that had been used for prior testing, which has included rigid ablators, flexible insulators and even reusable metallic TPS. PAIDAE modified the sled to the dual wedge configuration shown in Figure 1, so that two test conditions could be run simultaneously. The desire was to run a nominal heat rate and an overtest condition of the same sample layup each test run. The dual wedge test fixture has one row of sample mounting locations, which are referred to as the forward location, positioned at about half the running length of the top surface of the wedge. At about two thirds of the running length of the wedge, a second test surface drafted up at five degrees relative to the first test surface for the remaining running length of the wedge test fixture, consequently the description double wedge. A second row of sample mounting locations in the middle of the running length of the second test surface is referred to as the aft location.

The test surfaces were constructed from a 0.313in thick aluminum base plate insulated with low density $\mathrm{SiO}_{2}$ foam, $\mathrm{FUSIO}_{2} \mathrm{~N}$ Foam 50, acquired from Rex Materials. The $\mathrm{SiO}_{2}$ insulator was bonded to the top surface of the aluminum base plate with RTV60. Gaps between the test surface plates were filled with Nextel rope and cemented with Sauereisen Cement No. 31. Test coupons were installed from underneath the test plate and bolted to the aluminum base plate. The gap around the test coupon and the $\mathrm{SiO}_{2}$ insulator was also filled with Nextel rope and grouted with Sauereisen Cement No. 31. The test plates had pressure taps drilled between each sample mounting location, and in addition to these surface pressure taps a transducer measured the pressure inside the cavity of the sled. This transducer made it possible to track the difference in pressure between the top and backside of the sample surface giving the pressure load applied to the sample. Side plates were mounted to either side of the sled to prevent spillage of the flow off the sides of the test surfaces preserving two-dimensional flow. The leading edge of the sled 
is a large solid piece of oxygen free copper the full width of the sled tapering to a 1/32in full radius edge. Cameras were positioned to image the forward and aft test locations.
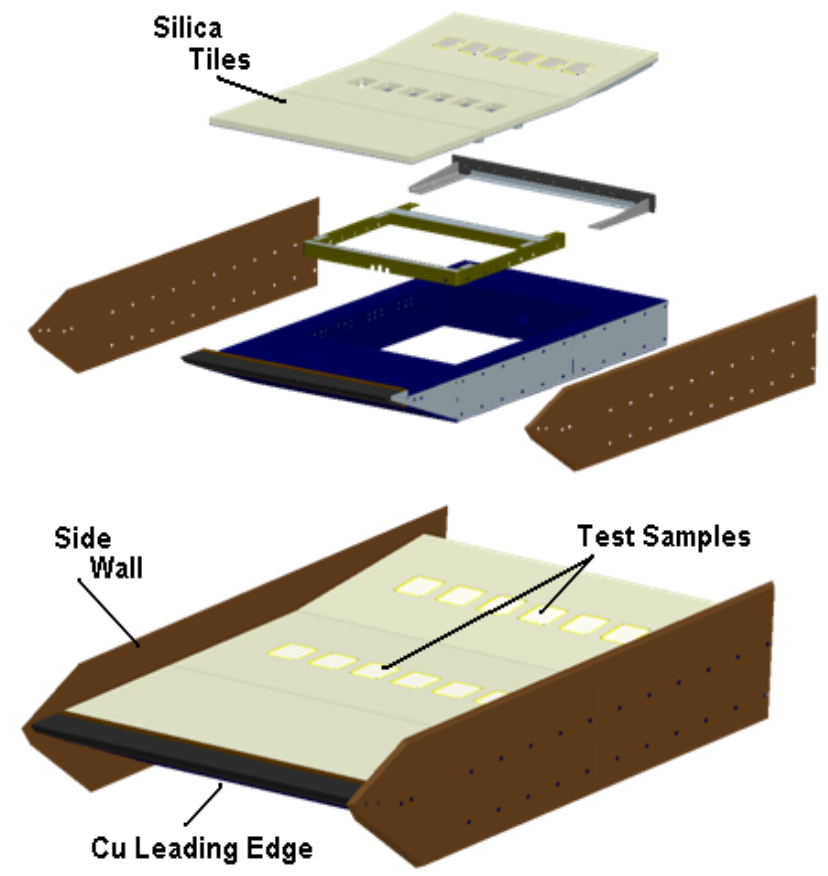

Figure 1. ProE Model of the PAIDAE test sled.

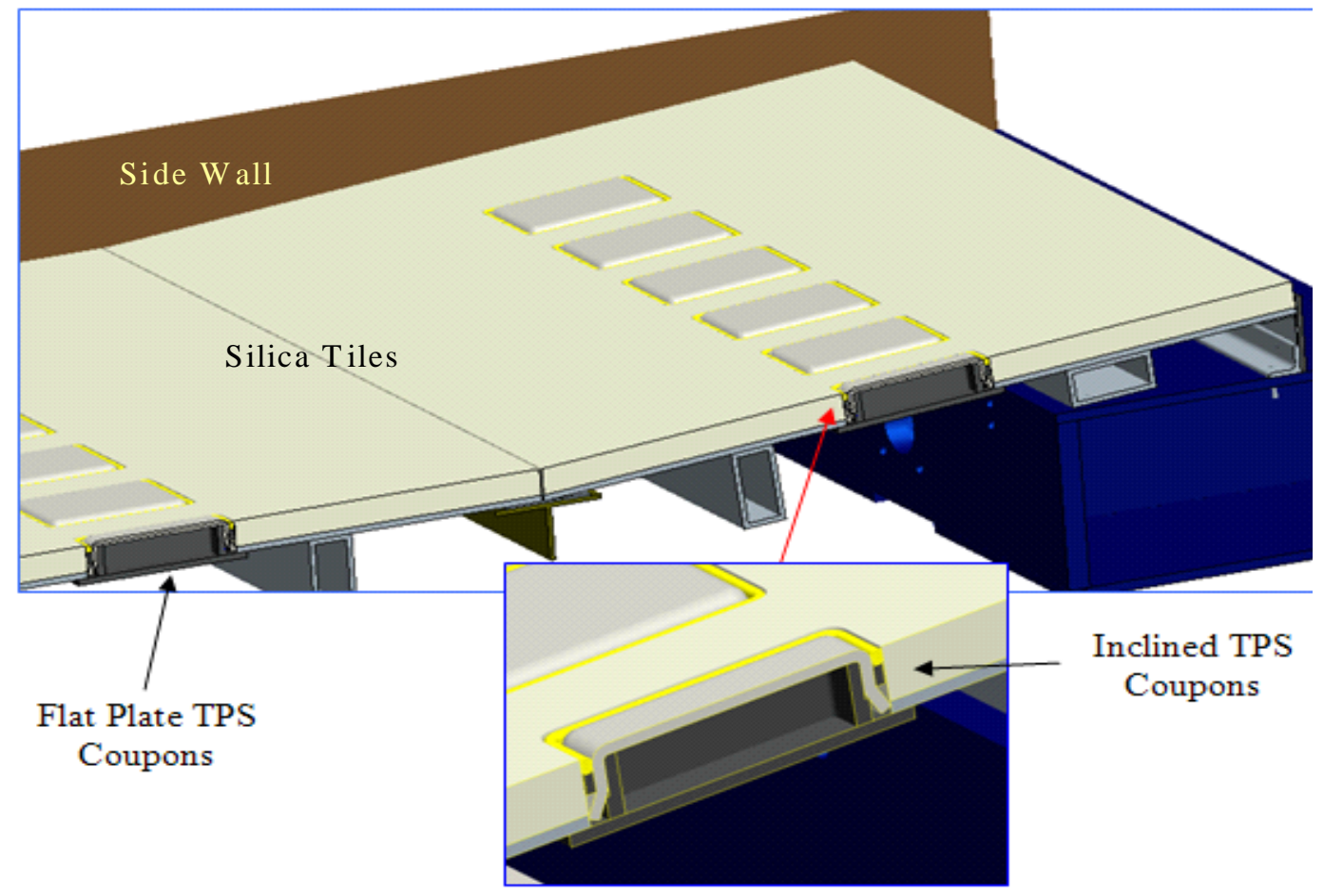

Figure 2. ProE Model of the PAIDE sled cutaway. 


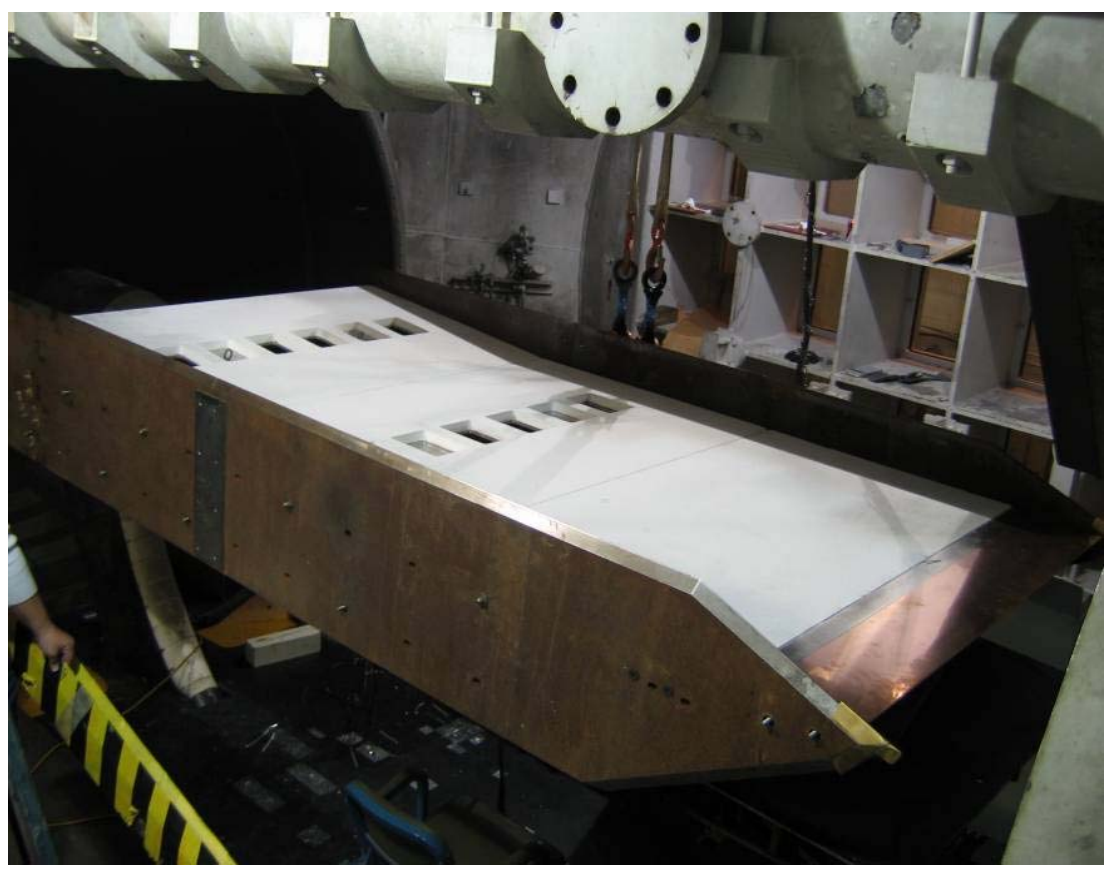

Figure 3. PAIDAE Dual Wedge Sled in 8Ft HTT Test Section

The sample holder for a test coupon is shown in Figure 4. A rectangular ring called the base ring is mounted on a mounting plate. The TPS coupon is stretched over the base ring with a tensioning ring, similar to a drum head. The tensioning ring is secured to the baseplate with threaded rods at each corner of the tensioning ring. The TPS coupon is pinched between the tensioning ring and a step on the base ring. The mounting plate of the sample holder is bolted to the back side of the test surface at the four corners of the sample holder and shimmed to position the coupon surface flush with the top surface of the test plate.

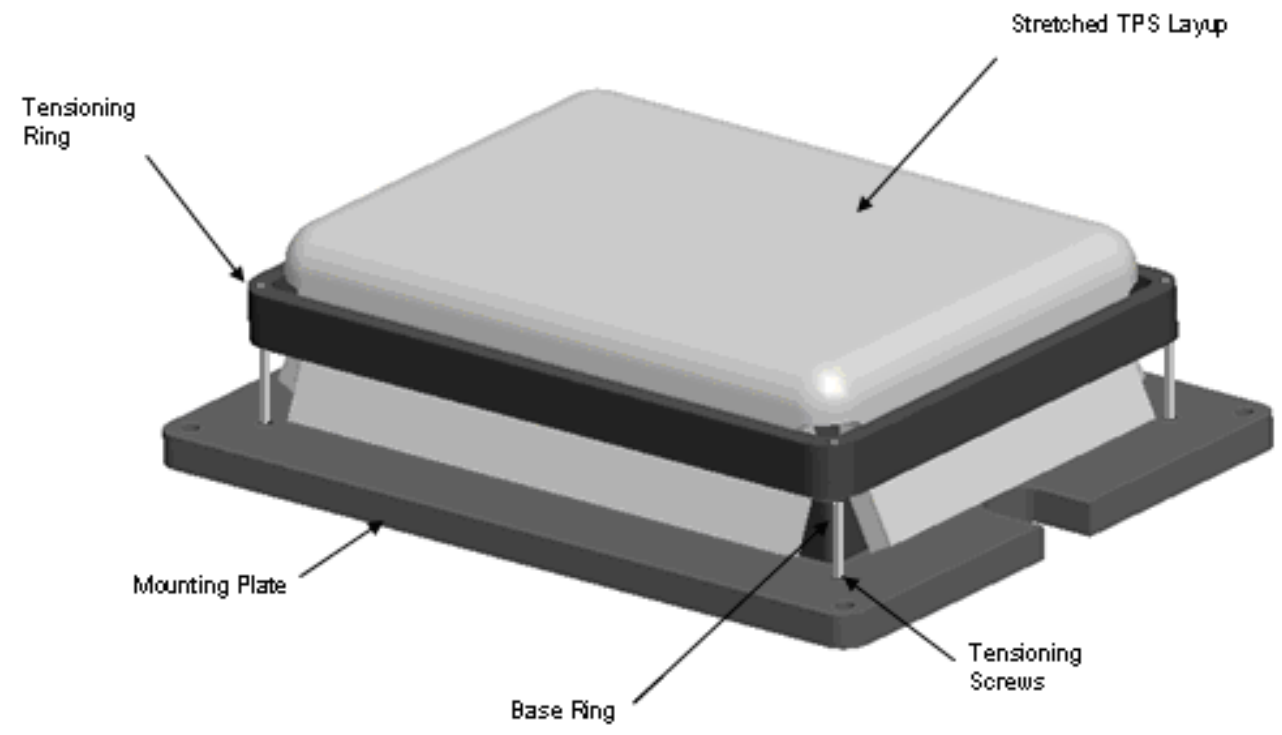

Figure 4. ProE model of a PAIDAE sample holder.

Sample coupons consisted of a maximum of six plies. The insulation plies were cut in a cruciform shape to reduce bunching of the material at the corners of the sample holder assembly. Each layup was instrumented with Type $\mathrm{K}$ thermocouples in the center and in the aft right corner (as viewed from up stream) of the exposed surface of the sample coupon (see Figure 5). The thermocouples at both the center and corner locations were staggered 1/8in for each subsequent layer to prevent a large surface distortion from developing where the thermocouples were concentrated (see Figure 6). A single ply of Kapton film was put on top of the sample layup to prevent damage to

American Institute of Aeronautics and Astronautics 


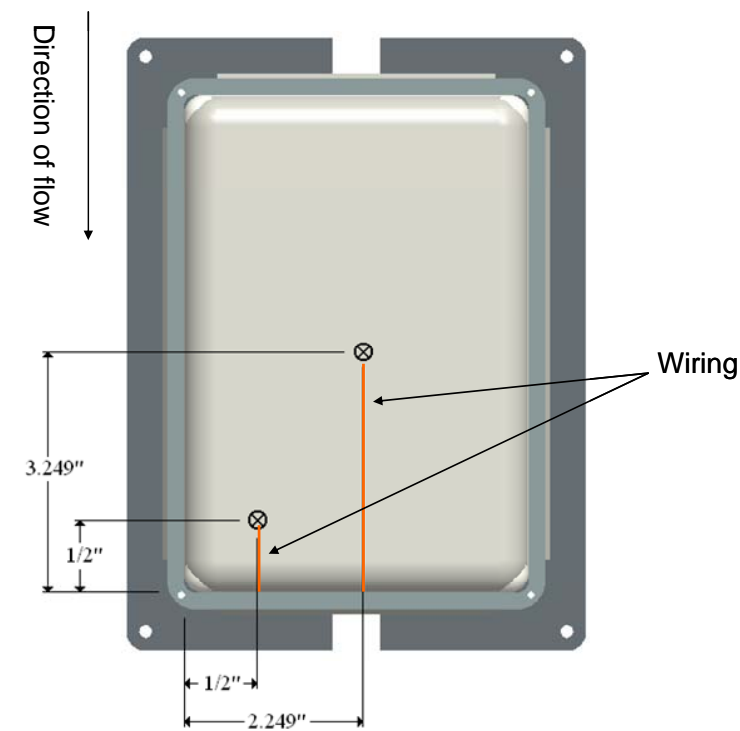

Figure 5. Thermocouple location.

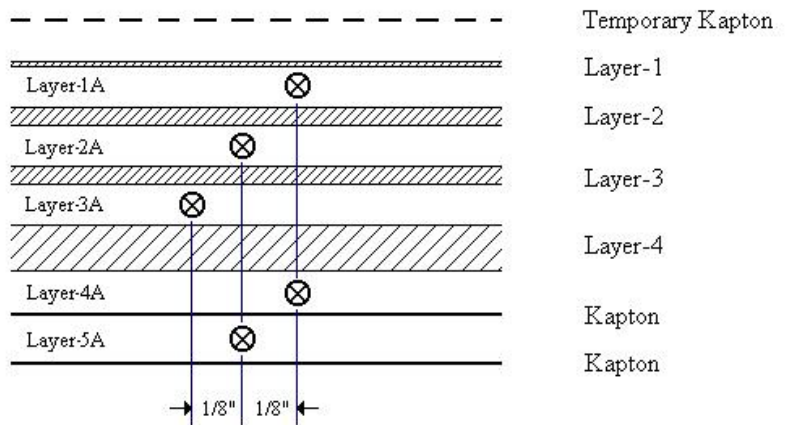

Figure 5. Thermocouple stagger between plies.

the outer ply of the sample coupon when installing it into the sample holder. Initially the outer Kapton ply was removed prior to installing the sample into the sled, but in the end the Kapton ply was left on for reasons discussed later in this paper. Figure 7 shows a sample coupon installed in the sample holder ready for installation into the sled.

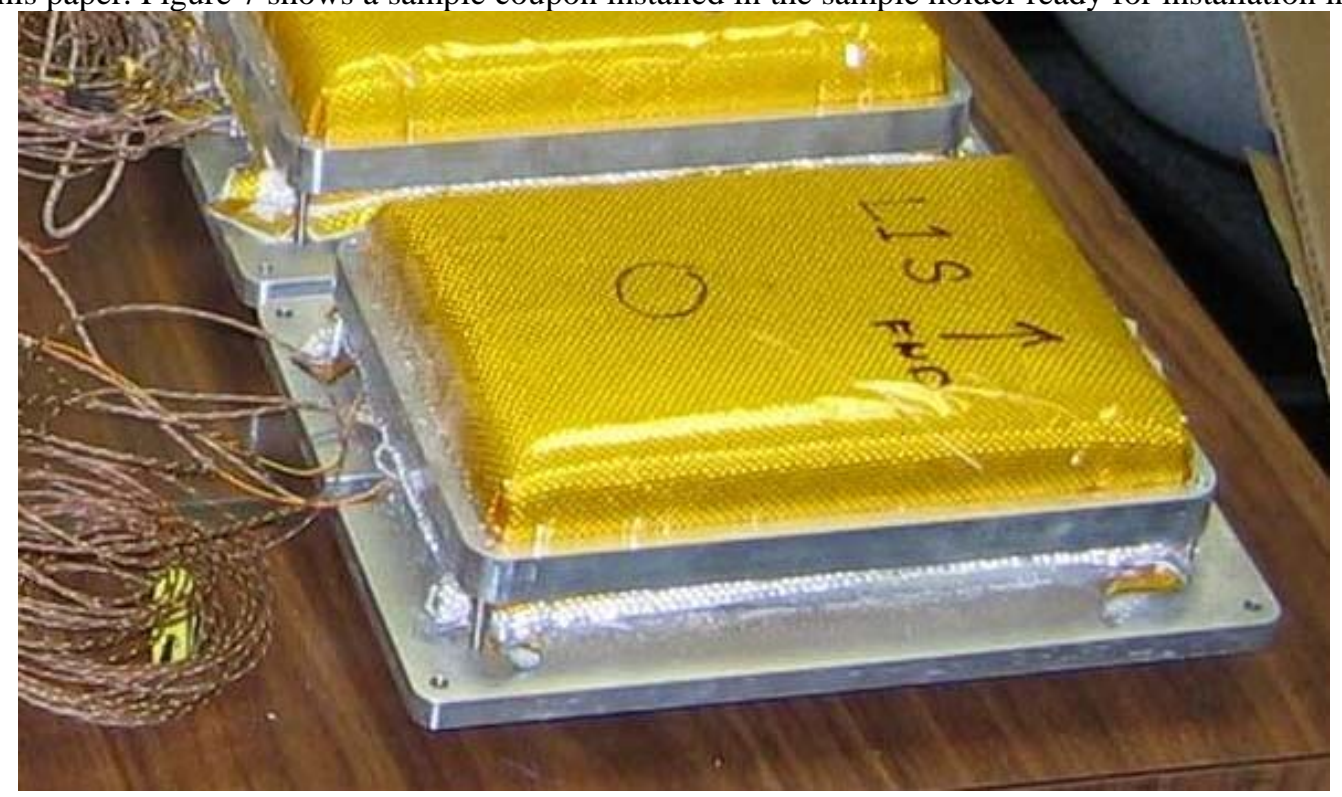

Figure 6. PAIDAE Sample ready for installation in the sled.

\section{PAIDAE Test Environment}

A Computational Fluid Dynamics (CFD) code, Vulcan v6.0.1, was used to model ${ }^{2}$ the sled in the test section at two separate flow conditions (see Table 1) and four different sled angles of attack (AoA). Plots of thermal flux and surface pressure versus sled running length were generated (see Figures 8 and 9). Tunnel personnel investigated previous testing that used the sled test fixture and that investigation led to the elimination of some potential combinations of tunnel flow conditions and sled AoA. Historical data indicated that at the low pressure flow conditions any sled AoA greater than $5^{\circ}$ caused enough flow blockage to "unstart" the tunnel. CFD modeling of inflatable deployable aeroshell concepts at peak pressure conditions predicted with entry simulations indicate peak surface pressures on a typical inflatable aeroshell should be on the order of 1 to $3 \mathrm{kPa}$. The surface pressure plots 
Table 1. Definition of High and Low Pressure Tunnel Conditions

\begin{tabular}{|c|c|c|}
\hline & Low Pressure & High Pressure \\
\hline $\begin{array}{l}\text { Composition - } \\
\text { Mole Fractions }\end{array}$ & $\begin{array}{l}\mathrm{N} 2=0.7154, \mathrm{O} 2=0.0237 \\
\mathrm{CO} 2=0.0841, \mathrm{H} 2 \mathrm{O}=0.1682 \\
\mathrm{Ar}=0.0086\end{array}$ & $\begin{array}{l}\mathrm{N} 2=0.7154, \mathrm{O} 2=0.0237 \\
\mathrm{CO} 2=0.0841, \mathrm{H} 2 \mathrm{O}=0.1682, \\
\mathrm{Ar}=0.0086\end{array}$ \\
\hline Flow Conditions & $\begin{array}{ll}\cdot & \text { Mach } 7 \\
\cdot & 813 \mathrm{~Pa}(0.118 \mathrm{psi}) \\
\cdot & 206 \mathrm{~K}(370 \mathrm{R}) \\
\text { - } & 2039 \mathrm{~m} / \mathrm{s}(6688 \mathrm{ft} / \mathrm{s}) \\
\end{array}$ & $\begin{array}{ll}\cdot & \text { Mach } 7 \\
\cdot & 1.62 \mathrm{KPa}(0.236 \mathrm{psi}) \\
\cdot & 206 \mathrm{~K}(370 \mathrm{R}) \\
\cdot & 2039 \mathrm{~m} / \mathrm{s}(6688 \mathrm{ft} / \mathrm{s}) \\
\end{array}$ \\
\hline
\end{tabular}

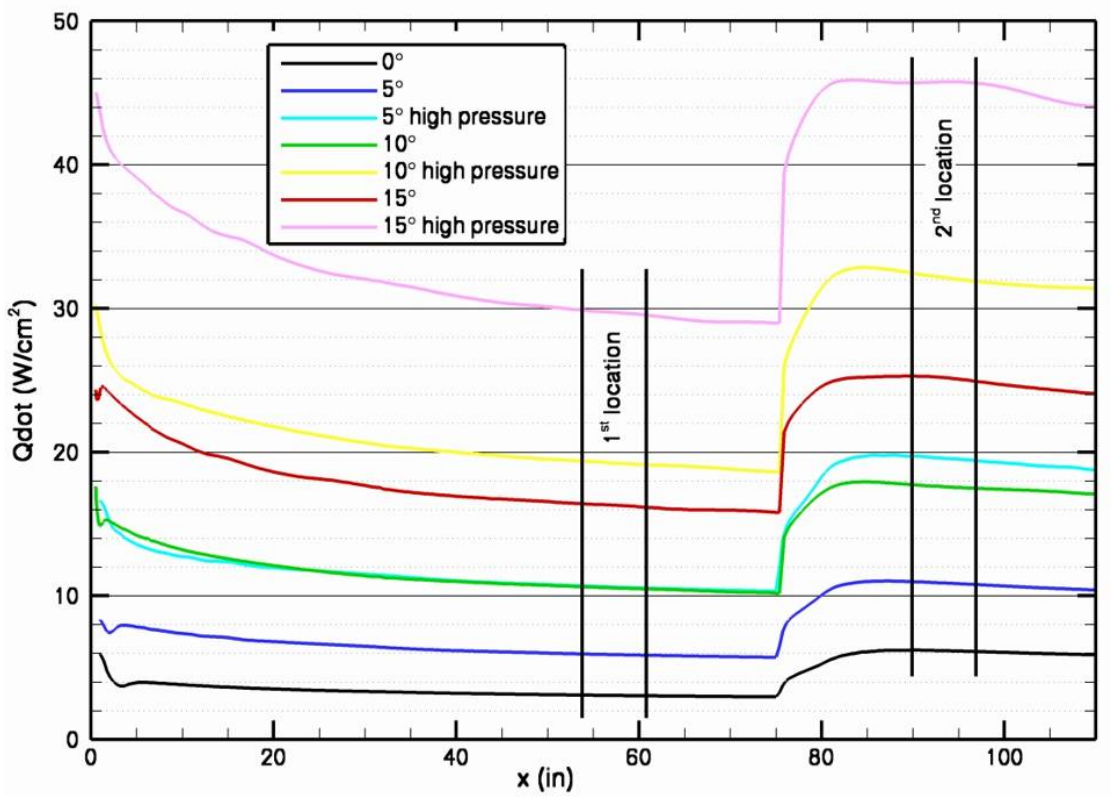

Figure 7. PAIDAE thermal flux vs. sled running length.

for the test sled indicated that for high pressure runs with sled AoA greater than $5^{\circ}$ the surface pressure at the sample locations is at least two to three times higher than the highest predicted peak flight conditions, so those combinations were eliminated from the potential test matrix. Initial sample layups were created for the remaining test environments from the candidate materials using engineering judgment. Thermal analysis ${ }^{3}$ was run for the candidate ply layups at the predicted environments to determine the maximum allowable run duration for the layup.

Calibration runs using an instrumented rake swung through the test section were made at the high and low pressure conditions to verify tunnel settings were producing the desired flow conditions in the test section. Surface pressure readings from the test plates taken during the test runs were used to validate the CFD predictions. 


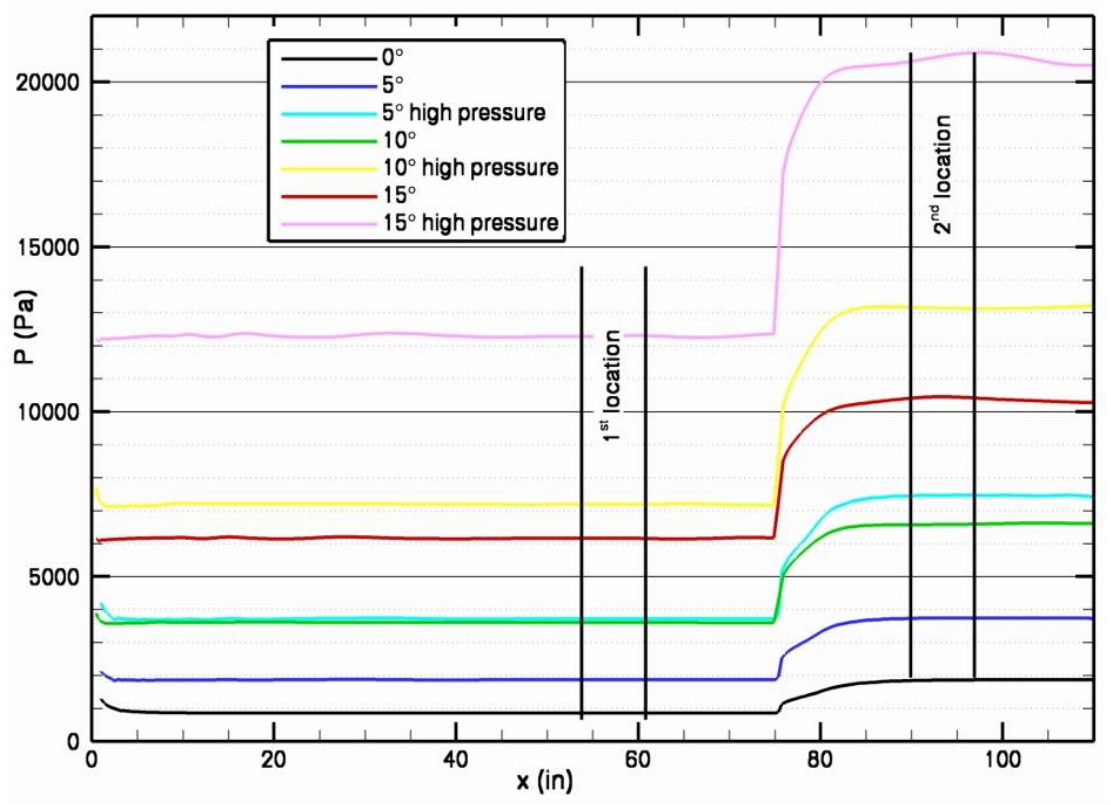

8. PAIDAE surface pressure vs. sled running lenth.

\section{PAIDAE Sample Layups}

As previously mentioned, three material categories were deemed necessary for layup construction: outer fabrics, insulators, and gas barriers. After searching commercially available material, contacting vendors, acquiring material properties data and wherever possible materials samples for evaluation, materials were selected for testing (see Table 2.).

Table 2. Materials selected for testing.

\begin{tabular}{|c|c|c|c|c|}
\hline & Manufacturer & Candidate & Description & $\begin{array}{l}\text { Reported Thermal } \\
\text { Capability }\end{array}$ \\
\hline \multirow{6}{*}{$\begin{array}{l}\text { Outer } \\
\text { Fabrics }\end{array}$} & \multirow[t]{3}{*}{$3 \mathrm{M}$} & AF-14 & $\begin{array}{l}\text { Type } 312 \\
\text { aluminoborosilicate fiber }\end{array}$ & $1100^{\circ} \mathrm{C}\left(2012^{\circ} \mathrm{F}\right)$ \\
\hline & & BF20 & $\begin{array}{l}\text { Type } 440 \\
\text { aluminoborosilicate with mullite }\end{array}$ & $1370^{\circ} \mathrm{C}\left(2500^{\circ} \mathrm{F}\right)$ \\
\hline & & XN513 & $\begin{array}{l}\text { Type } 720 \\
\text { aluminosilica fiber with mullite }\end{array}$ & $1400^{\circ} \mathrm{C}\left(2552^{\circ} \mathrm{F}\right)$ \\
\hline & \multirow{2}{*}{$\begin{array}{l}\text { Hitco Carbon } \\
\text { Composites }\end{array}$} & Refrasil UC100 & acid leached amorphous silica & $982^{\circ} \mathrm{C}\left(1800^{\circ} \mathrm{F}\right)$ \\
\hline & & $\begin{array}{l}\text { Refrasil } 1554 \\
\text { (Irish Cloth) }\end{array}$ & $\begin{array}{l}\text { acid leached amorphous silica, fired } \\
\text { and treated with chromic oxide }\end{array}$ & $1260^{\circ} \mathrm{C}\left(2300^{\circ} \mathrm{F}\right)$ \\
\hline & ILC Spec & T300 & PAN & $2000^{\circ} \mathrm{C}\left(3632^{\circ} \mathrm{F}\right)$ \\
\hline \multirow[t]{5}{*}{ Insulators } & \multirow[t]{2}{*}{ Aspen Aerogel } & Pyrogel 3350 & $\begin{array}{l}\text { silica aerogel with reinforced non- } \\
\text { woven carbon and glass fiber batting }\end{array}$ & $325^{\circ} \mathrm{C}\left(725^{\circ} \mathrm{F}\right)$ \\
\hline & & Pyrogel 6650 & $\begin{array}{l}\text { silica aerogel with reinforced non- } \\
\text { woven carbon and glass fiber batting }\end{array}$ & $650^{\circ} \mathrm{C}\left(1200^{\circ} \mathrm{F}\right)$ \\
\hline & \multirow{2}{*}{$\begin{array}{l}\text { Hitco Carbon } \\
\text { Composites }\end{array}$} & Refrasil 1800 & amorphous silica batting & $982^{\circ} \mathrm{C}\left(1800^{\circ} \mathrm{F}\right)$ \\
\hline & & Refrasil 2000 & $\begin{array}{l}\text { amorphous silica batting treated to } \\
\text { reduce residual shrinkage }\end{array}$ & $1093^{\circ} \mathrm{C}\left(2000^{\circ} \mathrm{F}\right)$ \\
\hline & Sigratherm & KFA5 & Carbon Felt & $\begin{array}{l}350^{\circ} \mathrm{C}\left(662^{\circ} \mathrm{F}\right)^{*} \\
1200^{\circ} \mathrm{C}\left(2192^{\circ} \mathrm{F}\right)^{* *}\end{array}$ \\
\hline \multirow{2}{*}{$\begin{array}{l}\text { Gas } \\
\text { Barriers }\end{array}$} & DuPont & Kapton VN & polyimide film & $400^{\circ} \mathrm{C}\left(752^{\circ} \mathrm{F}\right)$ \\
\hline & UBE & Upilex-S & $\begin{array}{l}\text { ultra-high heat resistant polyimide } \\
\text { film }\end{array}$ & $500^{\circ} \mathrm{C}\left(932^{\circ} \mathrm{F}\right)$ \\
\hline
\end{tabular}

* Oxidizing environment

** Non-oxidizing environment 
The materials were combined into layups using engineering judgment grouping and sequencing materials using manufacturer's advertised temperature limits, emissivities, and conductivities. One goal of the PAIDAE team was to improve the models of the materials in the layups and correlate them to test data, with the goal to have a relatively accurate performance prediction for any combination of candidate materials. Table3 lists the layups tested in the 8ft HTT.

Table 3. PAIDAE TPS layup list.

\begin{tabular}{||c|lll||}
\hline Layup & Outer Fabric & Insulator & Gas Barrier \\
\hline \hline L1 & AF14 & Pyrogel 6650 & Kapton $(2 X)$ \\
\hline L2 & BF20 & Pyrogel 6650 & Kapton $(2 X)$ \\
\hline L3 & AF14 $(2 X)$ & Pyrogel 6650 & Kapton $(2 X)$ \\
\hline L4 & BF20 (2X) & Pyrogel 6650 & Kapton $(2 X)$ \\
\hline L5 & XN513 & Refrasil 1800, Pyrogel 3350 & Kapton $(2 X)$ \\
\hline L6 & Refrasil C1554-48 & Pyrogel 6650 & Kapton $(2 X)$ \\
\hline L7 & Refrasil C1554-48 & Refrasil 1800, Pyrogel 3350 (2X) & Kapton $(2 X)$ \\
\hline L8 & Refrasil C1554-49 & Refrasil 2000, Pyrogel 6650 & Upilex (2X) \\
\hline L9 & Refrasil UC100-28 & KFA5, Pyrogel 3350 & Upilex (2X) \\
\hline L10 & T300 Cloth (3X) & KFA5 & Upilex (2X) \\
\hline L11 & BF20 (2X) & Refrasil 1800, Pyrogel 3350 (2X) & Upilex (2X), Kapton \\
\hline L12 & Refrasil UC100-28 (2X) & KFA5, Pyrogel 3350 & Upilex (2X), Kapton \\
\hline L13 & BF20 & Refrasil 1800, Pyrogel 6650 & Upilex (2X), Kapton \\
\hline \hline
\end{tabular}

Each layup was tested in both a quilted and non-quilted configuration. This approach was selected to determine if there would be an appreciable increase in the survival of samples with the presence of the quilting yarns and also to determine if the quilting yarns would impact locally the thermal protection of the fabric ply, adjacent to its neighboring outer ply. The quilted samples were fabricated with a pre-fired amorphous silica cord having a nominal diameter of 0.040 inches. Manufacturer's data indicated that the material was thermally stable as it could operate continuously at temperatures up to $982^{\circ} \mathrm{C}\left(1800^{\circ} \mathrm{F}\right)$ and would not melt until $1593^{\circ} \mathrm{C}\left(2900^{\circ} \mathrm{F}\right)$. The quilting was configured in orthogonal stitch rows with roughly 2in spacing (see Figure 10.). The stitch rows were oriented on the samples so that the stitch rows were at $45^{\circ}$ angles to the flow, and penetrated only the outer and insulative layers.

Thermocouples were integrated to the plies prior to quilting and measures were taken not to dislodge a thermocouple after quilting. Thermocouples were affixed to the un-quilted samples in their proper locations with Kapton tape, and the plies were laid in a fixture designed for loading the layup on the sample holder (see Figure 11.). 


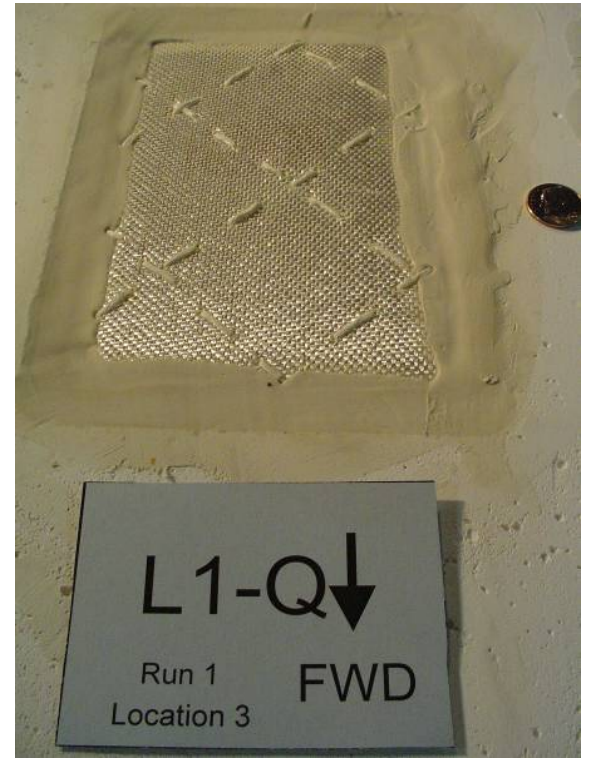

9. Typical PAIDAE quilted sample.

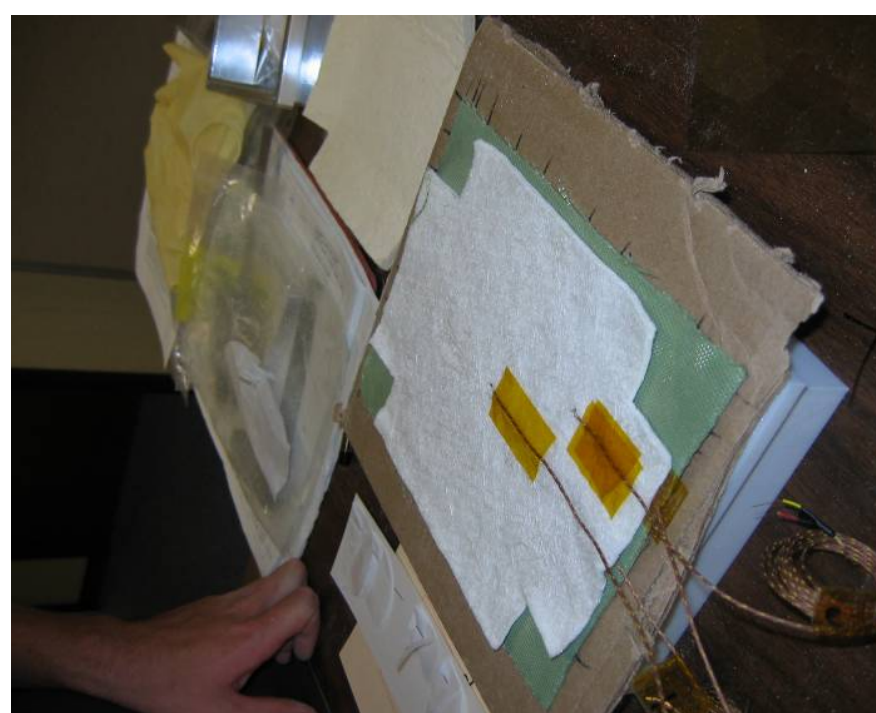

Figure 10. Installation of thermocouples on an unquilted ply.

\section{PAIDAE Test Runs}

Figure 12 shows the sled loaded for the first run of test samples with the leading edge of the sled not visible to the right of the figure. The forward sample locations are on the right of the figure and the aft, ramp, sample

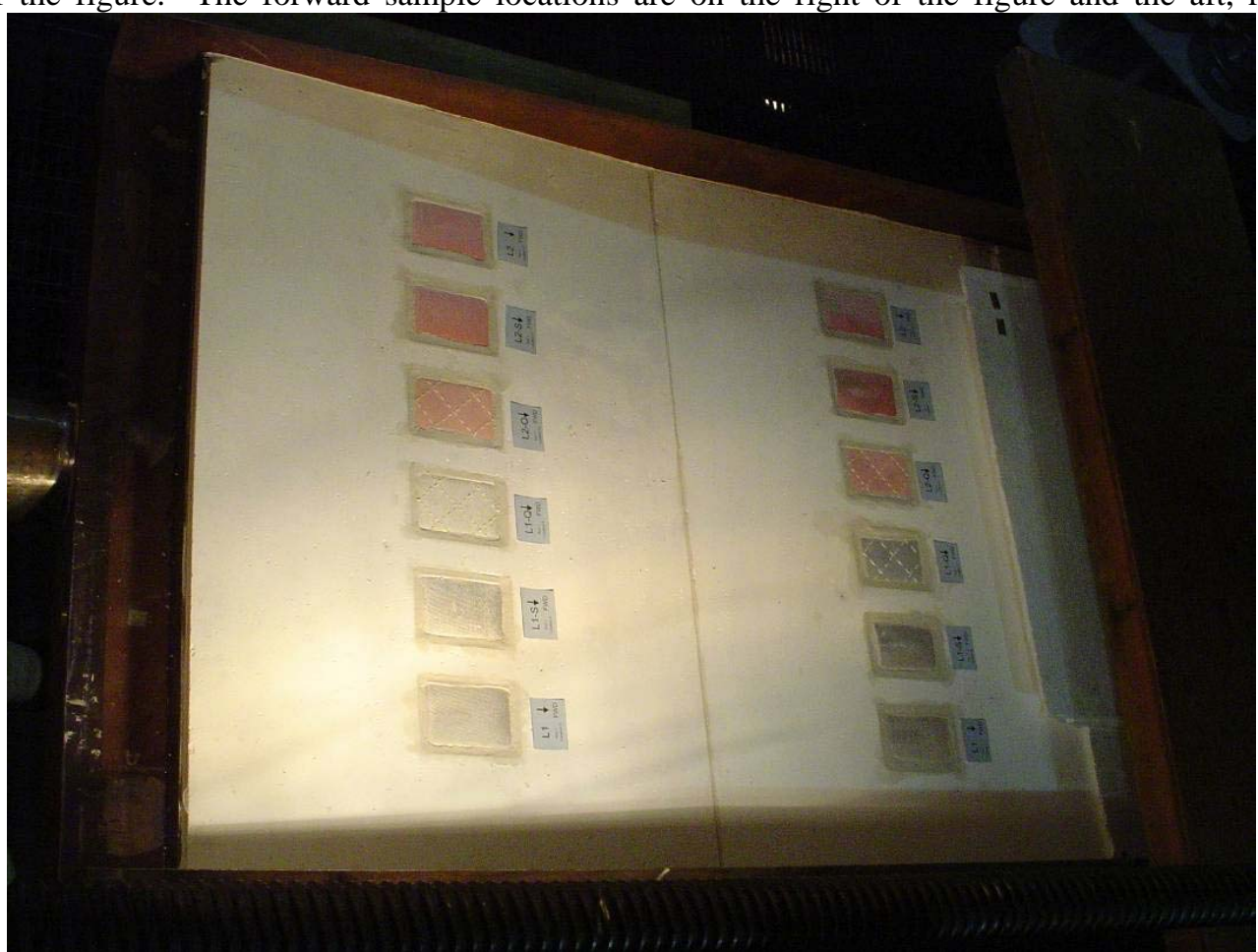

Figure 11. PAIDAE sled loaded for first run with samples.

locations are on the left. The forward locations were numbered 1 through 6 as viewed in the figure from the bottom to the top and the aft locations were numbered 7 through 12 as viewed in the figure from the bottom to the top. Two layups were tested each sled run, one layup set in forward locations 1 through 3 and aft locations 7 through 9, and the second layup set in forward locations 4 through 6 and aft locations 10 through 12. Samples were either quilted or un-quilted and the sample was either supported or unsupported. For supported samples the cavity in the ring base 
was filled with low density (2lb/ft $\left.{ }^{3}\right)$ carbon foam which supported the sample while maintaining a near adiabatic back wall. The supported samples were representative of locations on an inflatable aeroshell where the TPS is directly in contact with inflatable structure. For unsupported samples the cavity of the ring base is open and the TPS coupon is allowed to scallop-in under the surface pressure load. The unsupported samples were representative of locations on an inflatable aeroshell not directly supported by the inflatable structure.

\section{A. Sample Run \#1}

Layups 1 and 2 were tested in this run with layup 2 recognizable in the pre-test photo by the pink sizing on the BF20 cloth. This was a low pressure run $90 \mathrm{sec}$ in duration with the sled pitched down to $5^{\circ}$ AoA. The sled AoA was set and then the sled was injected once the low pressure conditions were established in the test section. The Sauereisen grout around the samples was not as smooth as we would have liked but it was the best transition we were able to achieve. After the end of the run the test surface had several damage sites that were of much greater concern than the wavy grout surface (see Figure 13.). A portion of the Nextel rope filling the gap between the first two test surface plates (visible in the lower left of the figure) had had broken free during the run and could be seen

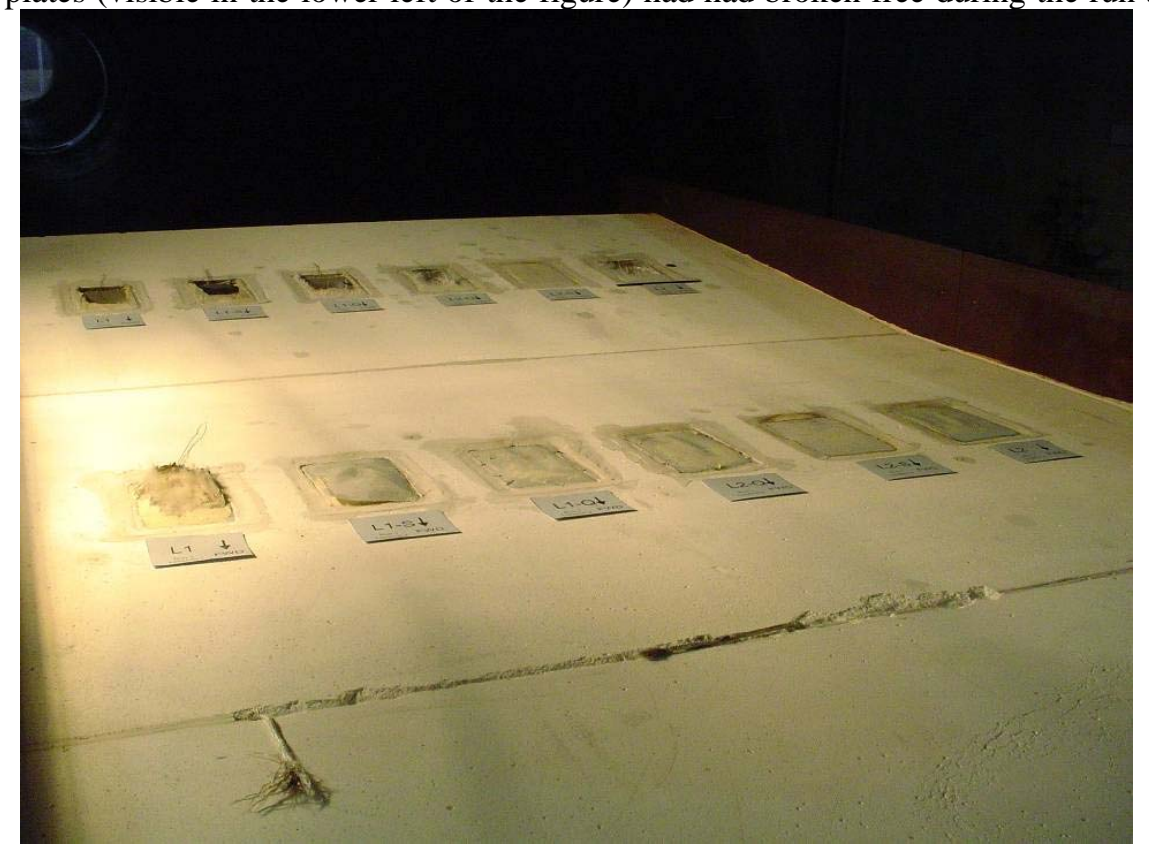

Figure 12. PAIDAE sled after the first sample run (sled leading edge off picture lower right).

flapping in the flow like a telltale. Pieces of the $\mathrm{SiO}_{2}$ insulator block chipped out of the test surface and impact points were visible on the inclined test surface. Several of the samples in the aft location failed before they were visible on the monitor. The failures were investigated prior to the next run. There were several likely causes for the failures: differential pressure during rapid depressurization causing the samples to be loosened enough to flag in the high shear pressure leading to mechanical failure, overloading the sample as it transition through the shear boundary of the tunnel flow, debris from the forward sled locations striking and damaging the samples leading to mechanical sample failure, and higher than predicted heat flux leading to mechanical failure. Unfortunately, there was inadequate instrumentation and video coverage to pinpoint a cause. Also of concern was the observation that the removal of the samples from the sled post-test imparted significant to the $\mathrm{SiO}_{2}$ foam around the sample locations. Progressively larger and larger areas of the $\mathrm{SiO}_{2}$ on the test surface needed repair for subsequent runs.

\section{B. Sample Run \#2}

The second sled run with test samples was to be a duplication of the previous run again using layups 1 and 2 . For this run the decision was made to inject the sled at a lower angle of attack and then pitch the sled down to the $5^{\circ}$ AoA test point. This was done to lower the effect of pressure spike experienced by the sample when crossing the shear boundary of the tunnel flow. Unfortunately, injecting the sled in this configuration resulted in an "unstart" of the tunnel destroying all samples on the sled. After researching the tunnel run history, the tunnel personnel discovered that for all runs previous runs the sled injection AoA was $5^{\circ}$ or greater. 


\section{Sample Run \#3}

The third run with samples was again a low pressure run with a 90sec duration at $5^{\circ}$ AoA using layups 5 and 6 . The sled injection angle was returned to $5^{\circ}$ AoA. Again upon injection numerous samples failed. All of the layup 6 samples failed, and two of the three layup 5 aft location samples failed. Location 7 layup 5 survived roughly 50 seconds of the 90 second run. Two of the three layup 5 samples in the forward location had nominal performance for the entire run. The sample in location 1 seen in Figure 14 showed surprising behavior. Even though the top XN513 fabric failed, and the first insulation layer, Refrasil1800, failed immediately after the top fabric failed, the

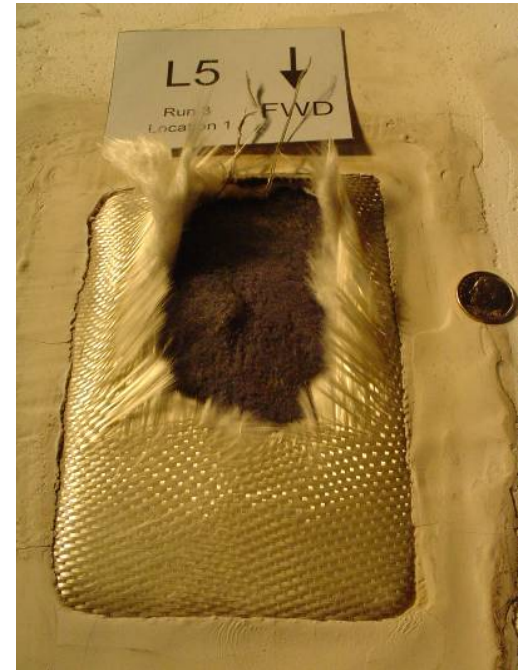

Figure 13. Run 3, Location 1,

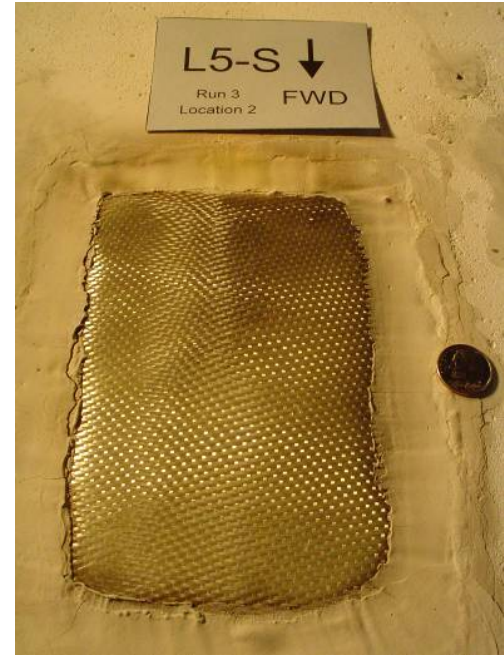

Figure 14. Run 3, Location 2,

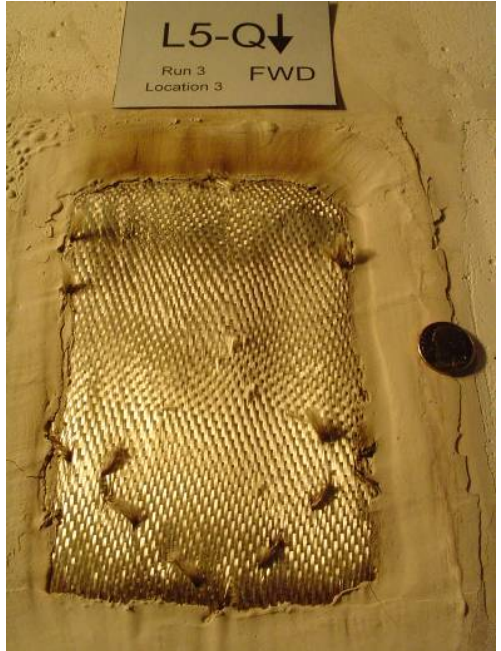

Figure 15. Run 3, Location 3, Layup 5, post-test.

underlying insulation, Pyrogel3350, survived 76 seconds of direct exposure to the test flow. The advertised maximum use temperature for Pyrogel3350 is only 350C, but the surface temperature of the material exposed to the flow was in excess of 700C. Figure 16 shows the quilted layup 5 sample in location 3 post-test. Most of the quilting yarn was burned or sheared off, but that would not be problematic for flight. The quilting will be required to maintain proper configuration of the layup when transitioning from the stowed to deployed state, but after the inflatable is deployed the quilting will no longer be necessary.

The failure of all of the layup 6 samples at sled injection in this run was investigated. ILC discovered the Sauereisen cement seriously embrittled the Refrasil1554 outer fabric. Further evaluations showed that all of the outer fabrics showed all fabrics experience some level of embrittlement from exposure to the cement solvents.

\section{Sample Run \#4}

The fourth run with samples was a duplication of the previous run. For this run however to rectify fabric embrittlement by the cement, the protective Kapton top ply was left on the sample when the void between the test fixture and the sample was filled with Sauereisen. Leaving the Kapton on was a trade off. Though the Kapton film would help protect the samples while they crossed the shear boundary of the test flow, and it would protect the outer fabrics from the solvents in the cement, it might have caused problems at rapid depressurization of the tunnel. It might also have meant that the cement would not help hold the sample in the test location. In an effort to minimize potential problems during tunnel rapid depressurization two vent holes roughly $3 / 8^{\text {th }} \mathrm{s}$ inch in diameter were punched in the outer Kapton ply to vent the gas trapped between the Kapton plies. Figure 17 shows a sample grouted in place with the protective Kapton film in place. Another issue was discovered with the use of the protective Kapton film when the cement cured. Because there was no adhesion to the Kapton, as the cement cured it pulled away from the film leaving a small raised lip around the joint, seen around the edges of the samples in Figure 18. The raised lip created a small channel around the sample that could have caused heating augmentation issues. To minimize the potential for heating augmentation the fine edges of unsupported cement were broken off prior to the test run, but there was not a smooth transition form the $\mathrm{SiO} 2$ foam to the test sample. Another concern addressed this test run was the potential issue of trapped gas between the outer protective layer and inner Kapton gas barrier plies auto inflating on tunnel depressurization. To that effect a pair of samples was built up in spare sample holders and placed in the test section outside of the flow near a window. A camera was set up to view the two samples during the run. Unfortunately, vibration of the camera at tunnel startup failed the power cord connection and the samples were not visible. Post-test the spare samples looked unchanged. As for the performance of the tested samples with the Kapton 


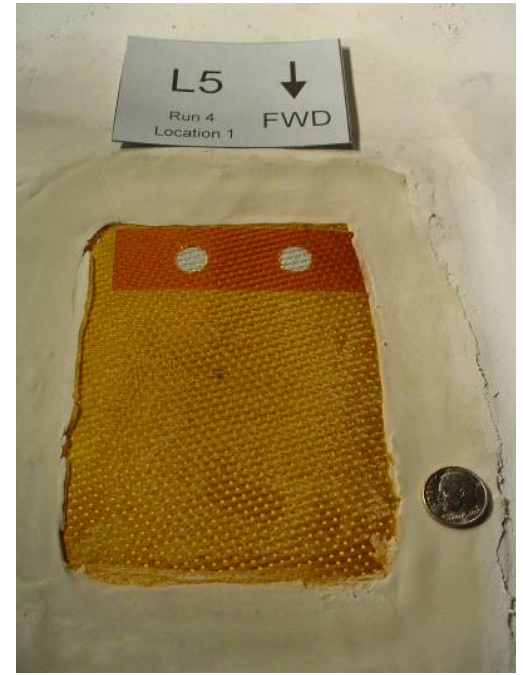

Figure 16. Run 4, Location 1, Layup 5, pre-test.

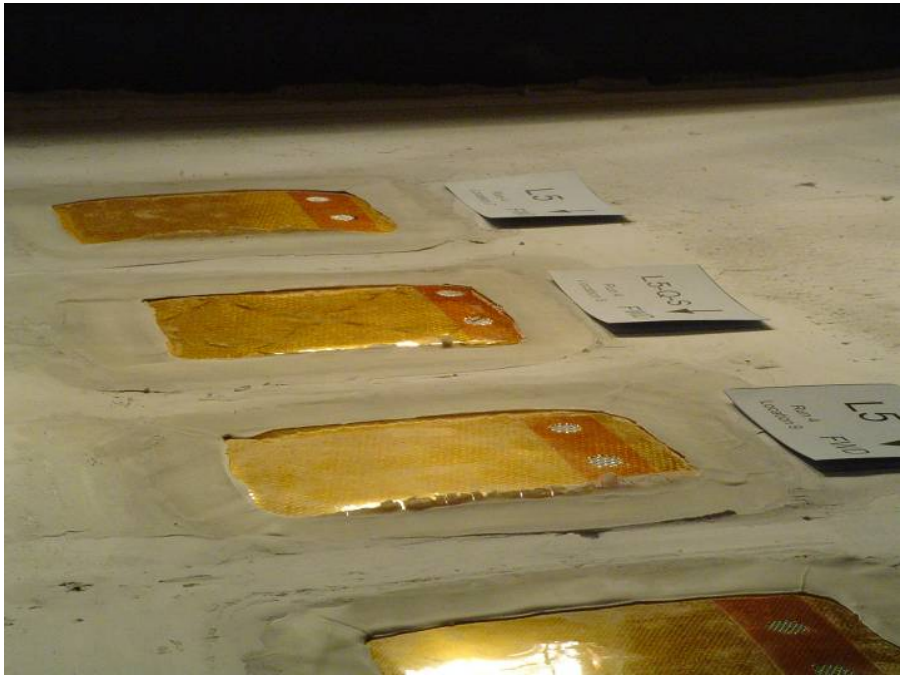

Figure 17. Sauereisen pulling away from Kapton Run 4, pre-test.

top ply, results were mixed. The Kapton appears to have done the job of protecting the sample through sled injection and rapidly burned off the samples within seconds as desired, but in this run, no samples survived on the ramp after the Kapton top ply burned. However, only one of the layup 6 samples in the forward sample location, location 6 , failed immediately after the Kapton ply burned off as opposed to all samples failing the previous run. The other two layup 6 samples in the forward location, locations 4 and 5, appeared fine post test. The thermocouple data for the sample in location 5, the quilted sample, showed nominal thermal performance. Thermocouple data for location 4 showed rather anomalous behavior. The red top center thermocouple trace (4_1) stopped tracking the predicted temperature and the traces of the in-depth center thermocouples (4_2 and 4_3) rose sharply well above predicted temperatures about 20 seconds into the run. After that sample was disassembled post test it was discovered that the

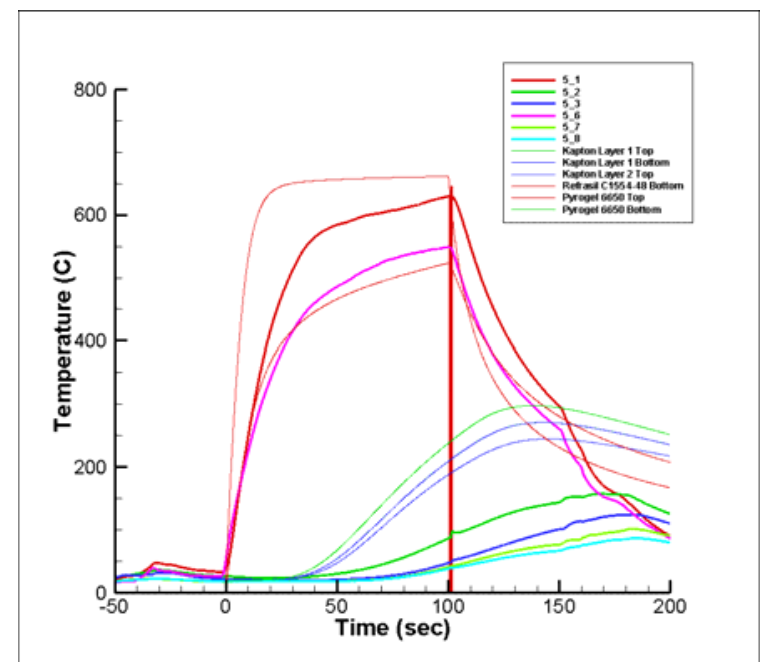

Figure 18. Run 4, Location 5, Layup 6, Thermocouple data.

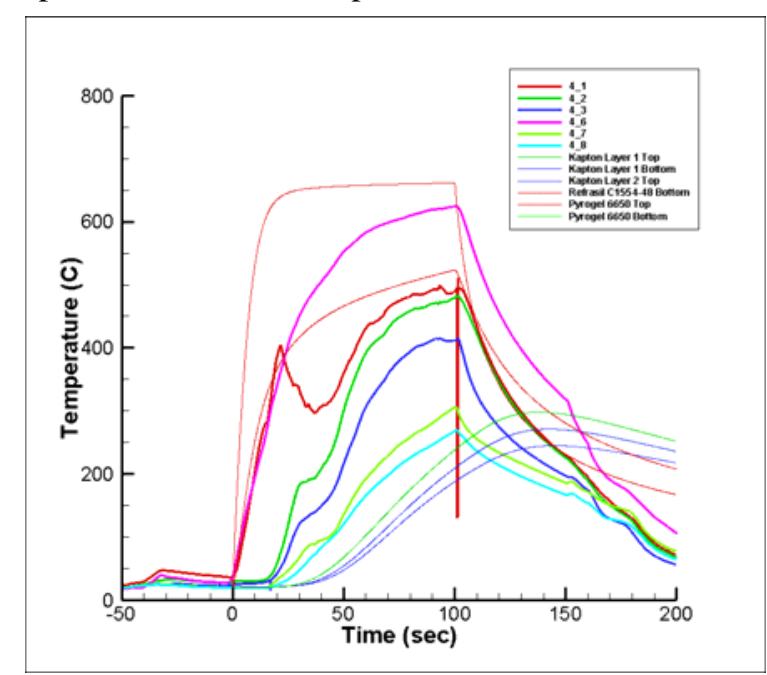

Figure 19. Run 4, Location 4, Layup 6, Thermocouple data.

center thermocouple between the top fabric and the insulator ply had bored a hole in the insulator resulting in unacceptable layup performance. Only the location 2 layup 5 sample perform nominally this run versus two in the previous run (see Figure 22.). In locations 1 and 3 the top XN513 fabric as well as the first insulating ply, Refrasil1800, failed shortly after the Kapton top ply burned off (Figure 23. typical). Once again, though, the Pyroel3350 survived exposed directly to the flow nearly the full duration of the run. 


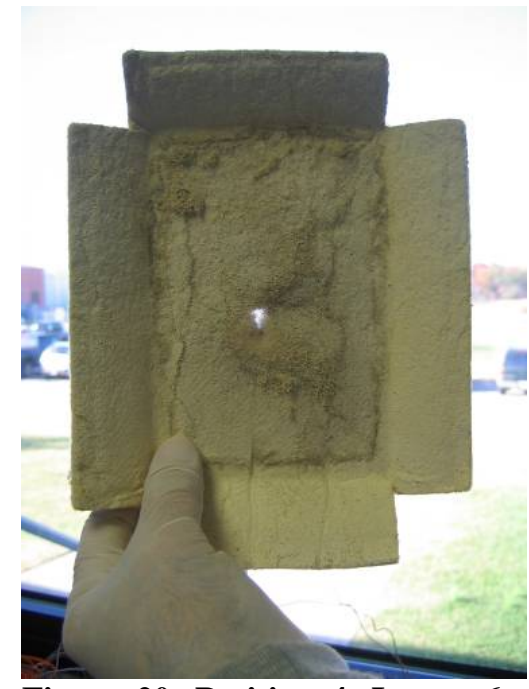

Figure 20. Position 4, Layup 6, Hole in 6650 insulating ply

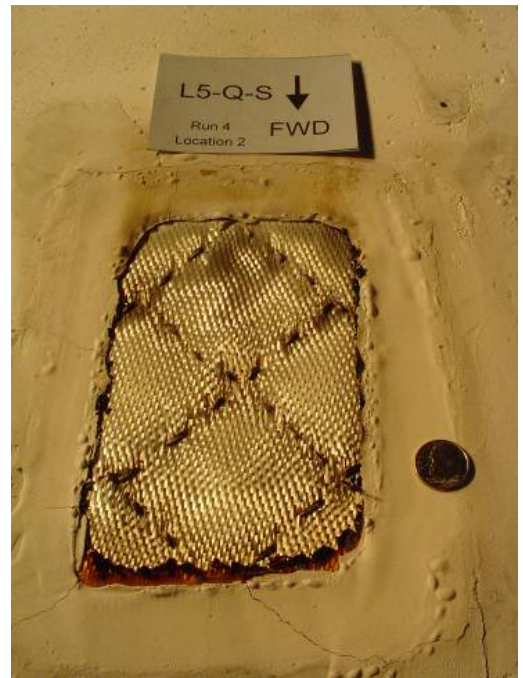

Figure 21. Run 4, Location 2, Layup 5, post-test.

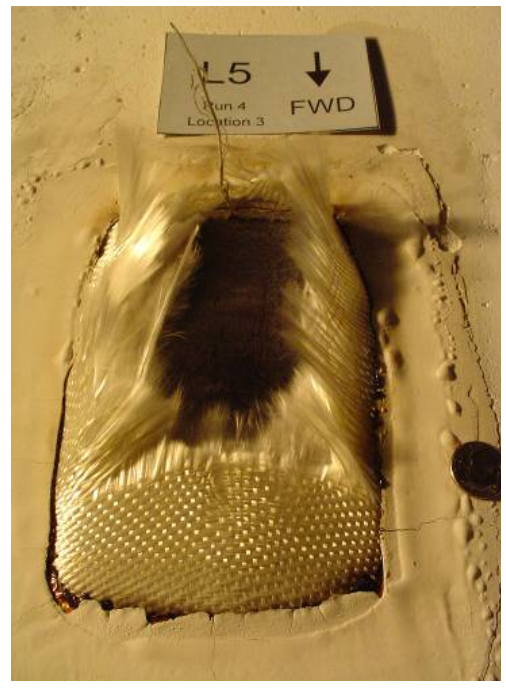

Figure 22. Run 4, Location 3, Layup 5, post-test.

\section{E. Sample Run \#5}

For the fifth run with samples, a tunnel start up abort occurred just prior to sled injection. Anomalous output from a valve indicator was the cause of the run abort. The valve was investigated and found to be operating nominally, Therefore another run attempt was made. This run duplicated the first run, but for three exceptions: 1) the protective Kapton outer ply was retained for sample installation 2) Sample locations 1, 6, 7, 8, 11 and 12 were not used due to the high sample failure rate at those locations, which were thought to be due to shocks coming off the tip of the sled side plates running on top of location 1, 6, 8 and 11. Each of those locations was filled with a plate and the plates were covered with Sauereisen (see Figures 24 and 25.). 3) Center thermocouples were deleted adjacent to the insulator because examination of the Pyrogel 6650 post run (which aborted prior to sled injection) revealed that those thermocouples were damaging the insulators during the vibration of tunnel startup. On the next attempt with

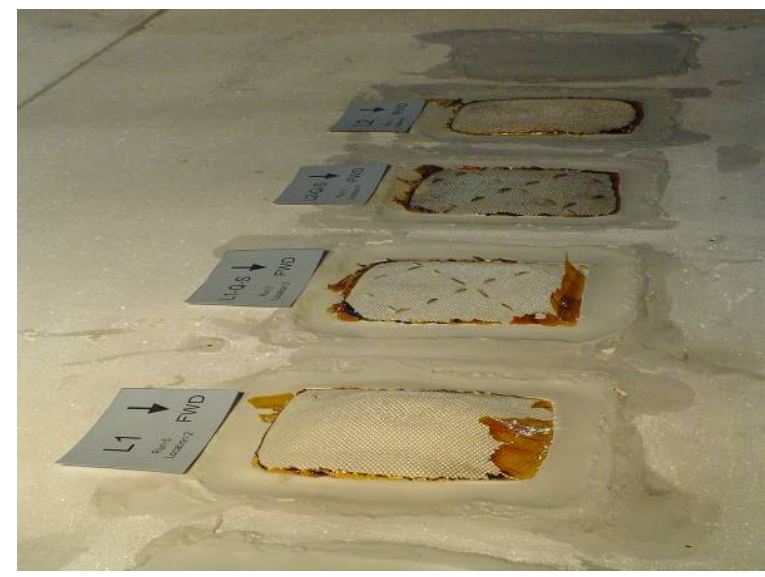

Figure 23. Run 5, forward samples post-test.

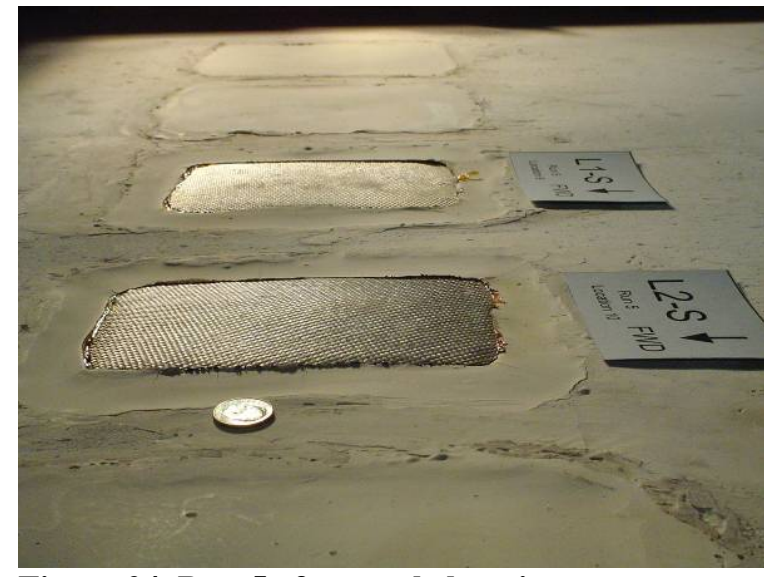

Figure 24. Run 5 aft sample locations post-test.

these samples the tunnel conditions were achieved and the sled injected nominally. The run was going well. All samples survived injection (see Figures 24 and 25.), and it appeared that most if not all samples would make it through the run. Unfortunately, 20 seconds into the 100 second run the same valve indicator initiated an auto shut down and sled retraction. Examination of the sample layups post test revealed that the Pyrogel6650 insulation ply was damaged on most layups (see Figures 26, 27 and 28.). The impregnated aerogel dust appeared to be being beaten out of the batt. 


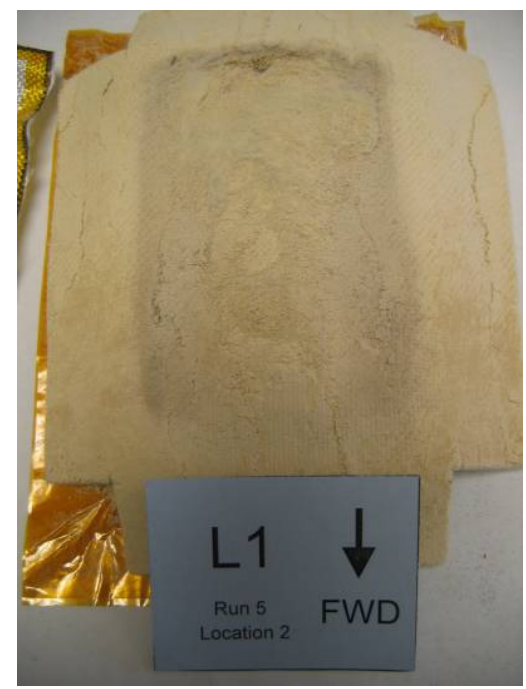

Figure 25. Run 5, Location 2, Layup 1, Pyrogel 6650 post-test.

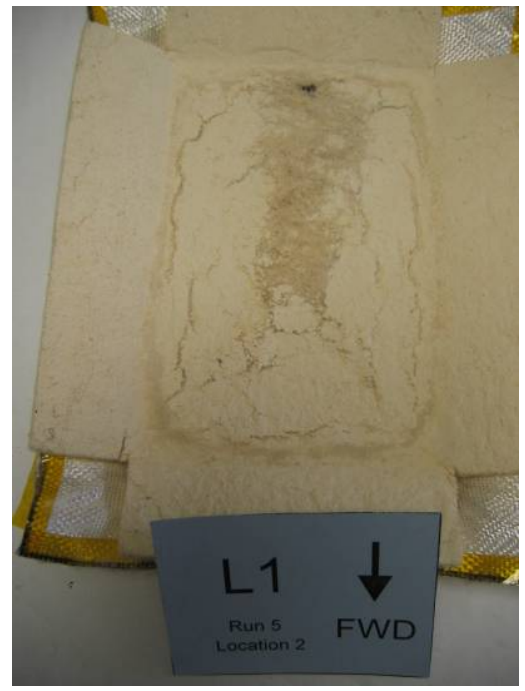

Figure 26. Run 5, Location 2, Layup 1, Pyrogel 6650 post-test.

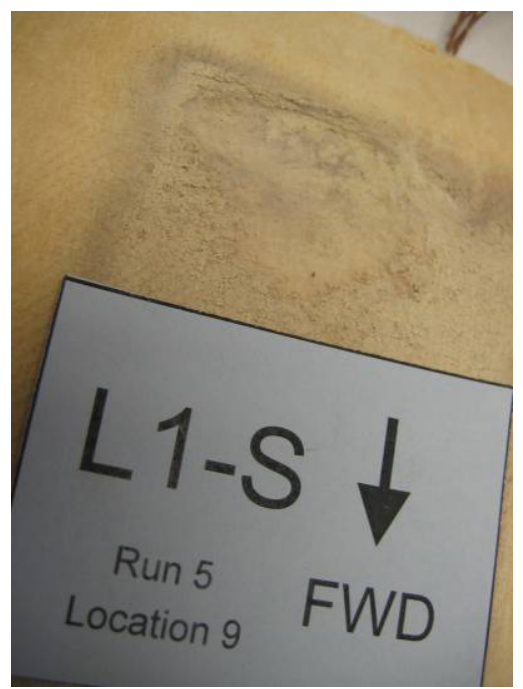

Figure 27. Run5, Location 9, Layup 1, Pyrogel 6650 post-test.

\section{F. Sample Run \#6}

The sixth run with samples was a final low pressure $5^{\circ} \mathrm{AoA}$ run. It appeared from the previous run that the derived sample installation method was sufficient. This run consisted of a combination of layups 2, 5 and 6, basically all of the spare layups we had from layups 1, 3, 5 and 6 . An additional concept to protect the ramp sample for sled insertion was tested this run. Shown in figure 29 a $5 / 16^{\text {th }}$ in plywood plate was sized to cover the sample so that it was supported by the base ring. The plate was held in place by the sacrificial outer Kapton ply, and the sample was grouted in with the plywood plate mounted on top. The plate was a large protuberance in the flow as the sample holder was shimmed to locate the sample surface flush with the test surface. Two attempts to run were aborted prior to sled injection. After the second abort the samples were removed and inspected because samples in locations 3, 4 and 9 did not appear taught in the holder after the two rapid depressurizations during failed run attempts. The samples were reassembled in the sample holder and approved for further testing. Tunnel operation on the third attempt to run these samples was nominal. The plywood plate survived sled injection into the flow and was released by the Kapton failing within a second of the sled making the centerline, but the sample still failed almost immediately after the plywood was released. Sample locations 4, 9 and 10 all failed immediately after the outer Kapton ply failed (layups 6, 5 and 5 respectively). Locations 2 and 5, layups 6 and 2 respectively survived the entire run with nominal performance. Location 3 with layup 5 in it once again had the XN513 top fabric fail almost

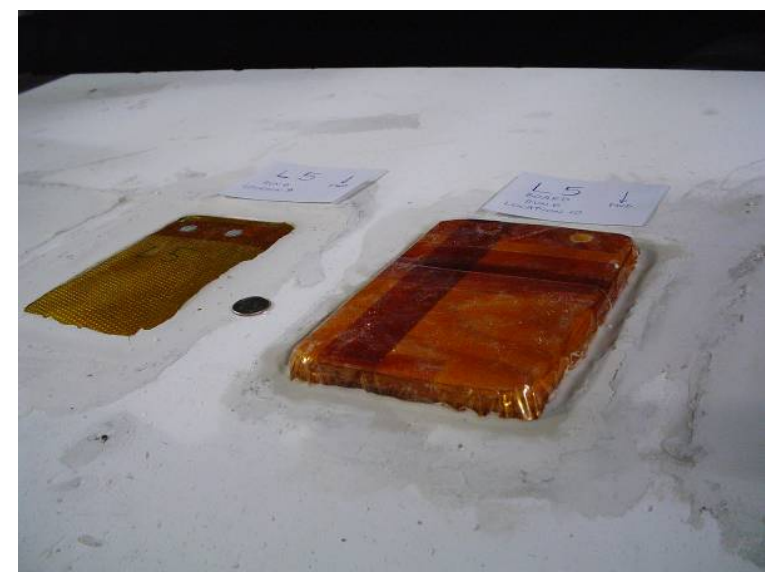

Figure 28. Run 6, Aft sample location, plywood plate right.

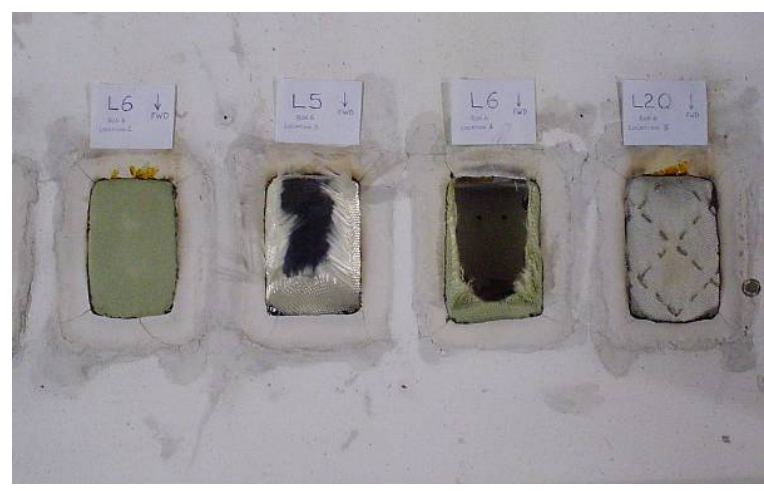

Figure 29. Run 6, forward location, post-test.

immediately after the sacrificial outer Kapton ply along with the first insulation ply (Refrasil1800). The underlying Pyrogel3350 ply survived direct exposure to the test flow for over 70seconds. 


\section{G. Sample Run \#7}

At this point in the testing the low pressure samples had been expended and the decision was made to press on to the high pressure $5^{\circ} \mathrm{AoA}$ condition. This seventh run with samples was populated with layups 3 and 4 and run time was 100 seconds. A 0.04in thick 2024 aluminum plate was manufactured to investigate protecting one of the ramp samples in the same fashion as the plywood plate in the previous run. Condensation in the test flow obscured the view of locations 9 and 10 at sled injection, so no conclusion can be drawn about the performance of the aluminum plate at location 9. The sample was seen flaring at roughly 7 seconds after sled injection and the thermocouple data indicates total sample failure at that time. Sample location 10, layup 4, survived sled injection and the sample functioned for a short duration. Approximately 10 seconds into the run the top fabric ply, BF20, began to fail. The second fabric ply survived for roughly 50 seconds, but at about 25 seconds thermocouple data between the second fabric ply and the insulator (see Figure 31. T/C 10_7) exhibited behavior consistent with the T/C boring into the insulator creating a thermal leak path to the underlying Kapton. The thermal short caused the Kapton temperature to climb rapidly to greater than $500^{\circ} \mathrm{C}$ at which point the sample failed. With a more durable insulator this sample would likely have survived a much longer duration. The sample in location 2, layup 3 , showed nominal performance for roughly 30 seconds until the top fabric ply, AF14, began to fail. At that point the heat appeared to have begun to infiltrate the layup and the back Kapton ply temperatures began to rise. Roughly 70 seconds into the test the second AF14 ply began to fail and the entire sample succumbed. The Pyrogel6650 insulator is just not a robust insulator and falls apart rapidly when exposed to vibration and the test flow. The sample in location 3, layup3, survived injection and performance appeared nominal on video for roughly 50 seconds. However, the trailing edge of the sample was definitely hotter than the center of the sample. Video of the sample showed the top fabric, AF14, maintaining integrity for roughly 75 seconds and the second ply letting go at roughly 97 seconds, just 3 second prior to sled extraction, but thermocouple data (see Figure 32.) indicates the insulating ply was losing integrity long before that. At approximately 40 seconds the center thermocouple next to the insulator (3_3) appears to have bored into the insulator and the back face temperature has begun to rise rapidly. The backface temperature was in excess of $450^{\circ} \mathrm{C}$ near sled extraction and the sample was on the verge of coming apart. The sample in location 4, layup 4, appeared to be in good shape post test but thermocouple data (see Figure 33.) indicated the insulating ply was severely degraded throughout the run. Examination of the sample out of the holder post test revealed that much of the impregnated aerogel was out of the batt (see Figure 34.). Again had a more durable insulation been used in this layup this sample would likely have performed well. The sample in location 5, layup 4, survived sled injection, but began to lose the top ply, BF20, roughly 35 seconds into the run. The second ply survived the remainder of the run, but thermocouple data indicated the insulator ply was deteriorating throughout the run.

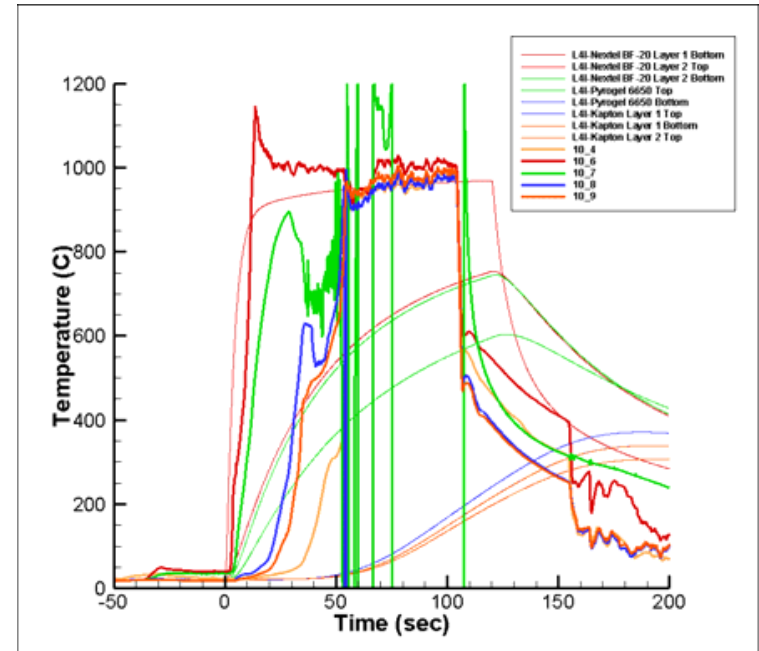

Figure 30. Run 7, Location 10, Layup 4 thermocouple data.

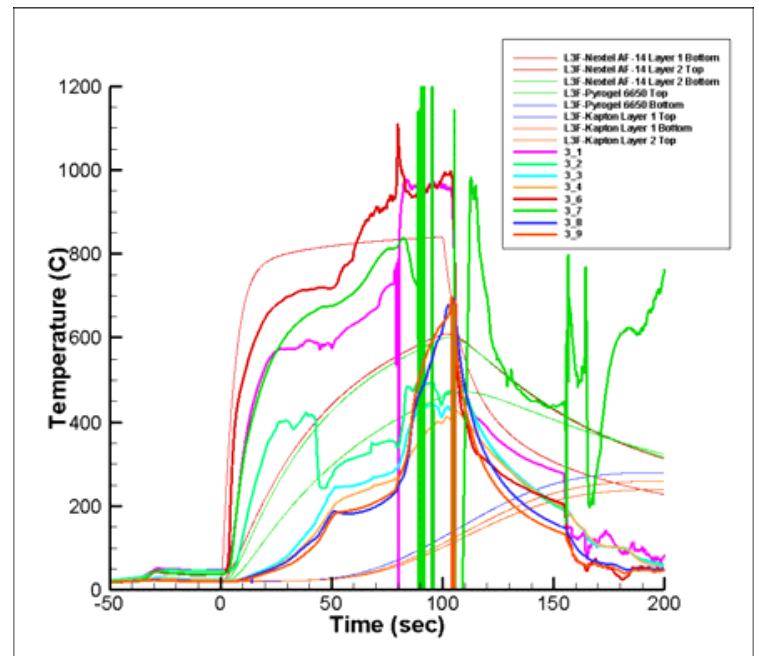

Figure 31. Run 7, Location 3, Layup 3 thermocouple data. 


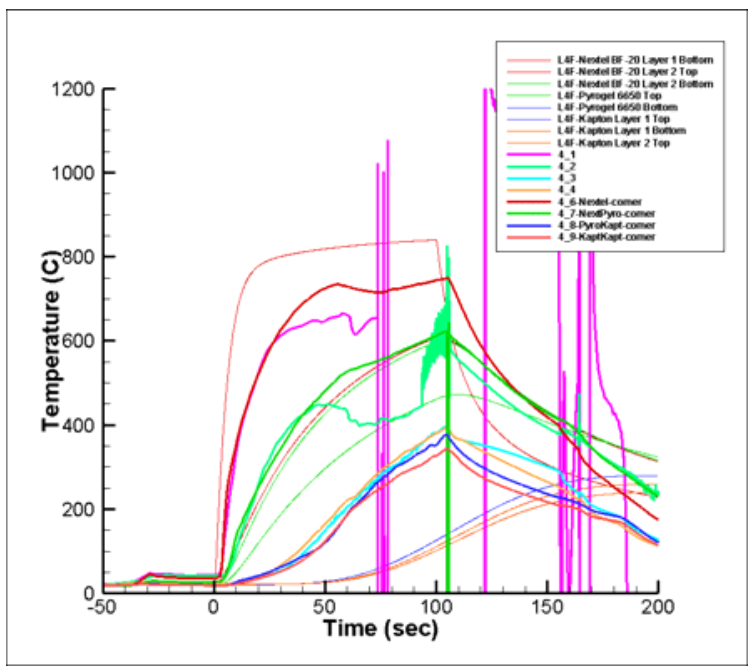

Figure 32. Run 7, Location 4, Layup 4
thermocouple data.

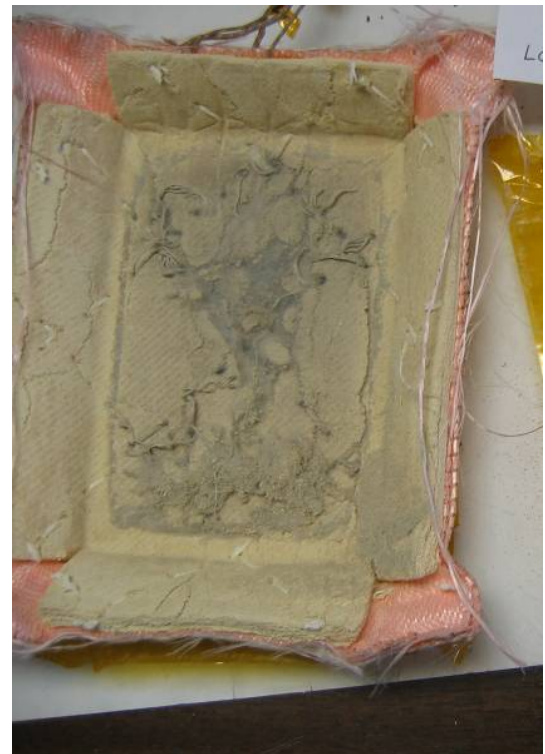

Figure 33. Run7, Location 4, Pyrogel 6650 post-test.

\section{H. Sample Run \#8}

The eighth run with samples was another high pressure run at $5^{\circ}$ AoA. Three aborted attempts to run occurred prior to getting a successful sled injection. The first two attempts exposed the samples to both tunnel vibration and rapid depressurization aborting just prior to model injection. The samples were removed from the sled and inspected. The quilted samples in locations 3 and 4 were replaced and all samples reinstalled on the sled. The next run attempt had a valve indication out of tolerance and aborted 15 seconds prior to sled injection, so the samples were only exposed to startup vibration and not the rapid depressurization, therefore the samples were inspected and used for the next attempt. On the fourth attempt the sled had a nominal injection and the test ran for roughly 57 seconds until a valve indicator caused another test abort. The team began to question the integrity of the test surface plates which had been patched with Sauereisen after every run (see Figure 35.). The samples in locations 9 and 10,

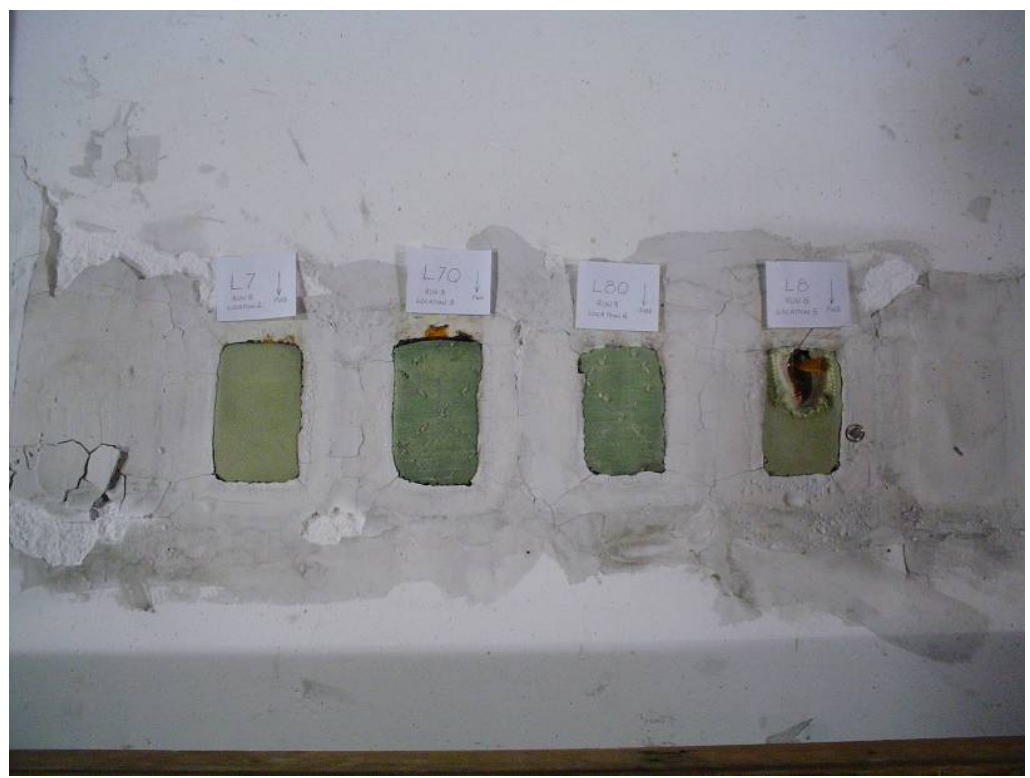

Figure 34. Run 8, forward locations post-test.

layups 7 and 8 respectively failed seconds after reaching the centerline. The sample in location 5, layup 8, the top fabric, Refrasil1554, failed at roughly 39 seconds and the insulating plies Refrasil2000 and Pyrogel6650 failed 
seconds after that. The samples in locations 2 , 3, and 4, Layups 7, 7, and 8 respectively survived the entire albeit curtailed run with near nominal performance (see Figures 36, 37 and 38.). The Refrasil1554 on the surviving samples was worn post-test and it was questionable as to whether those fabrics would have survived a full duration (100sec) run.

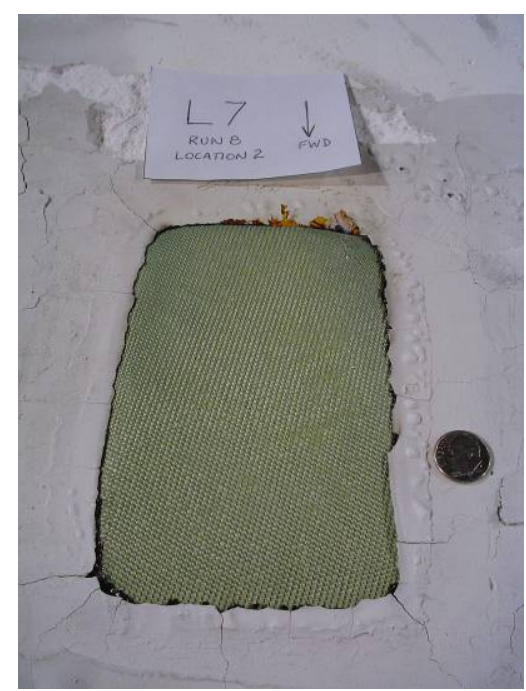

Figure 35. Run 8, Location 2, Layup 7 post-test.

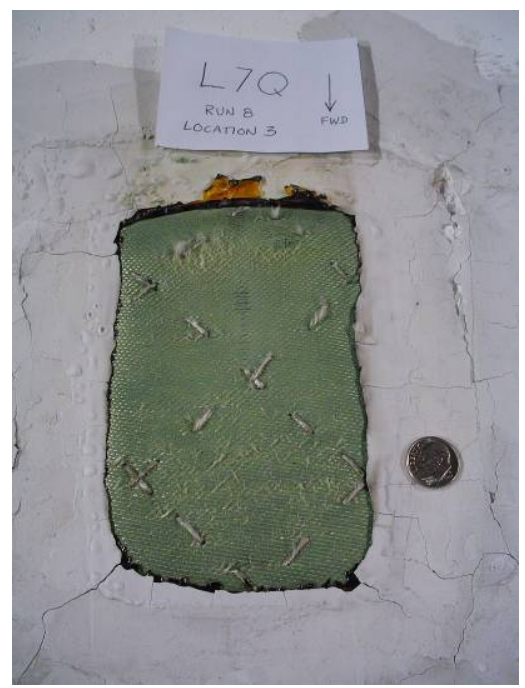

Figure 36. Run 8, Location 3, Layup 7 post-test.

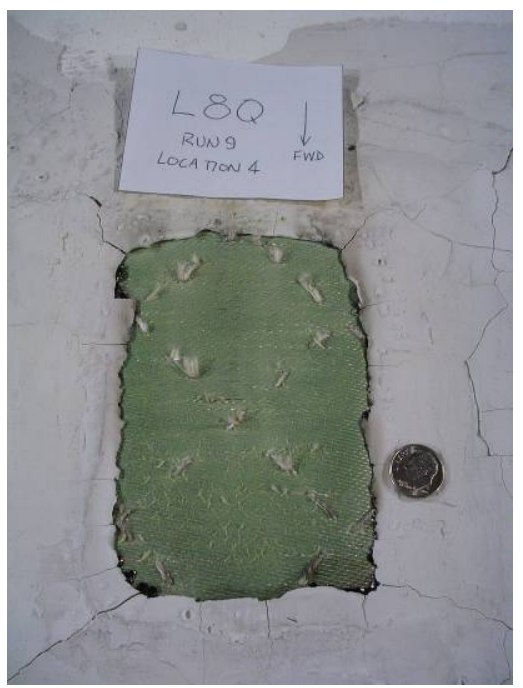

Figure 37. Run 8, Location 4, Layup 8 post-test.

\section{Sample Run \#9}

The ninth run with samples was a high pressure run at $5^{\circ}$ AoA populated with layups 9 and 10 as well as two hybrid layups (11 and 12) built to for the aft locations. The hybrid layups incorporated Upilex gas barrier plies between the outer fabric plies. Sled injection went nominally on the first try, so it seemed our trouble with tunnel gremlins was finally over. Sample location 10 did not survive more than a couple of seconds after the Kapton ply burned off. Surprisingly sample location 9, layup 11, survived the entire run (see Figure 39.) with phenomenal performance, the backface temperature hardly changed throughout the test (see Figure 40.). Sample locations 4 and

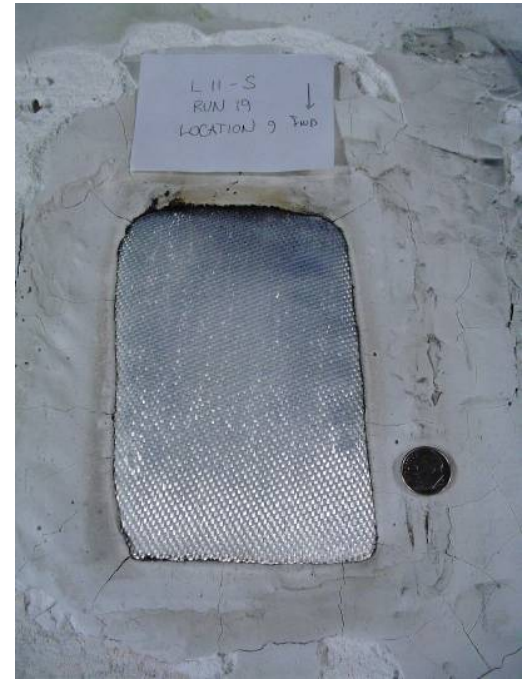

Figure 38. Run 9, Location 9, Layup 11 post-test.

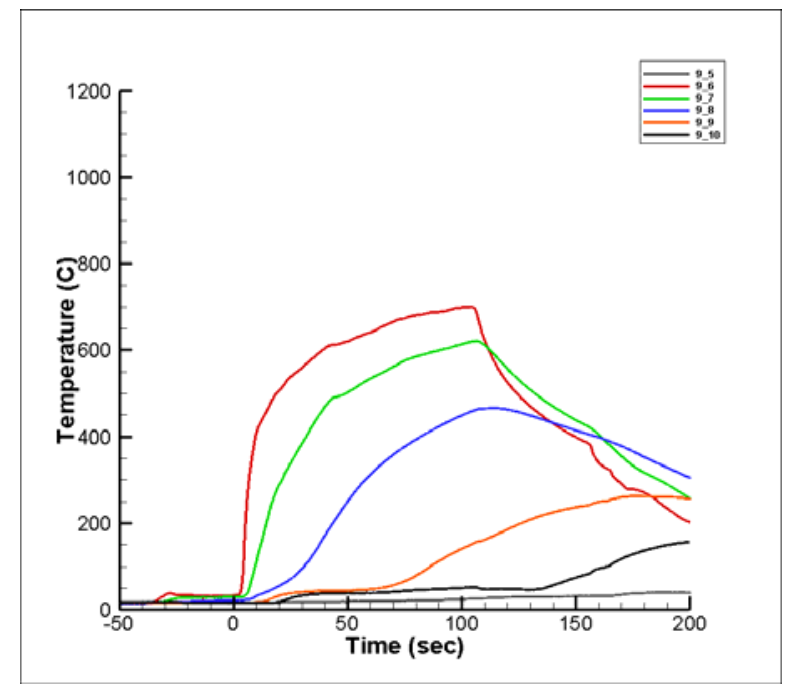

Figure 39. Run 9, Location 9, Layup 11, thermocouple data.

5, layup 10, failed rapidly. These samples had uncoated T300 outer fabric and they flashed not long after exposure to the flow. The carbon felt insulating ply, KFA5, did not fair much better when exposed directly to the flow and failed after roughly 7 seconds of exposure at both locations. Locations 2 and 3, layup 9, performed well even when the sample was exposed to a hot jet channeling through a slot in the $\mathrm{SiO}_{2}$ where the material was breaking up (see Figure 41.). The carbon felt insulating ply in layup 9 did not sustain combustion even though it had obviously 
charred in the location of the jet impingement, discovered when the samples were examined post test (see Figure 42.).

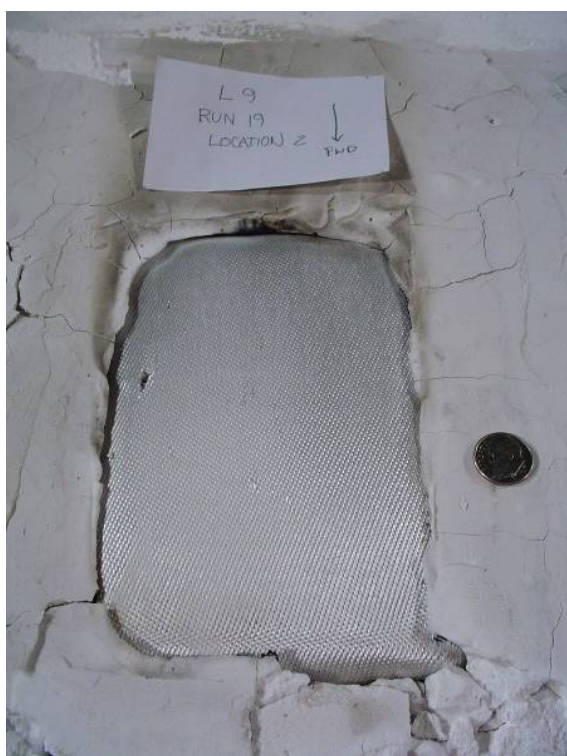

Figure 40. Run 9, Location 2, Layup 9, post-test.

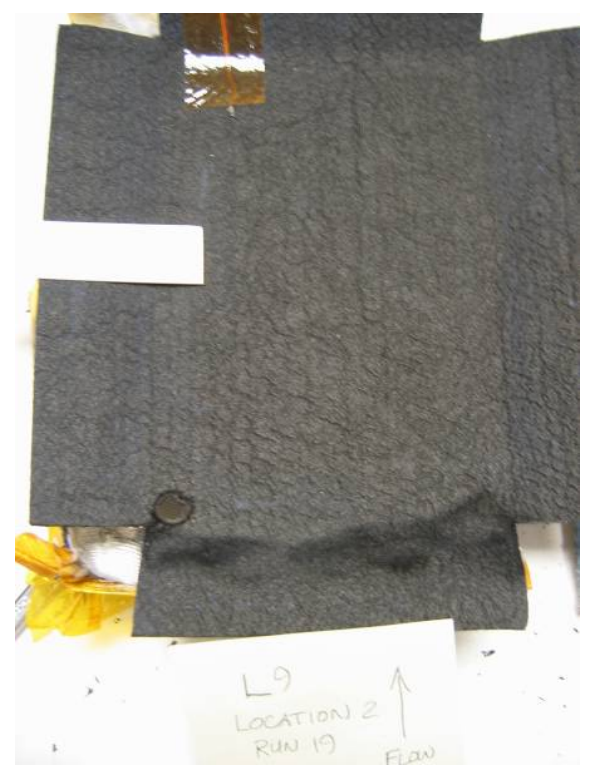

Figure 41. Run 9, Location 2, Layup 9, KFA5 ply, bottom, post-test.

\section{J. Sample Run \#10}

The final run was a repeat of the eighth run with layups 7 and 9 in the forward mounting locations. Layup 11 was used again, this time in location 10 and another hybrid layup, 13, was constructed for location9. Hybrid layup 13 was investigating whether it was the outer Upilex plies that were making layup 11 successful, by constructing a less durable layup, but incorporating the Upilex. Sample location 9 began to fail roughly 16 seconds into the run and was completely failed by 24 seconds. Sample location 10 survived injection. The sample experienced nominal performance for roughly 60 seconds until the top ply, BF20, failed. The second fabric ply, BF20, failed at roughly 85 seconds. The sample survived through model extraction 15 seconds later, although post test examination revealed the insulating plies were progressively failing (see Figure 43.). This is good data for these materials indicating that this combination has a graceful progression to failure when exposed to $\sim 20 \mathrm{~W} / \mathrm{cm} 2$ flow with very high surface shear. The thermocouple data in figure 44 shows the insulating plies continued to perform well even when the outer plies are failing. Sample locations 2, 3 and 5 (layups 7, 7 and 8 respectively) survived this run with nominal

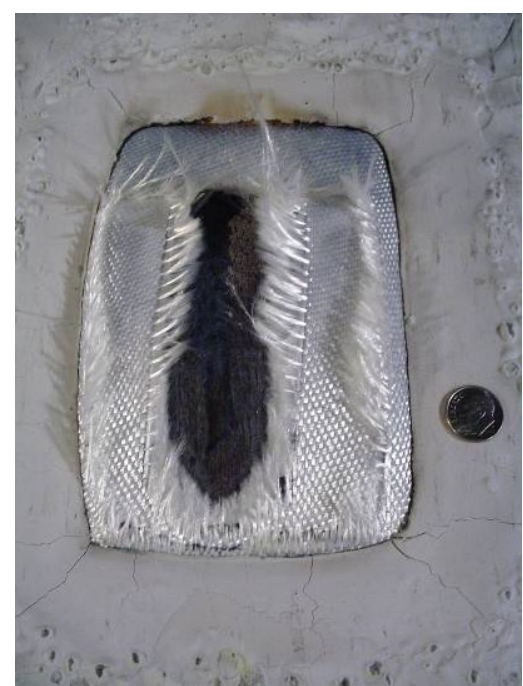

Figure 42. Run 10, Location 11, Layup 11, post-test.

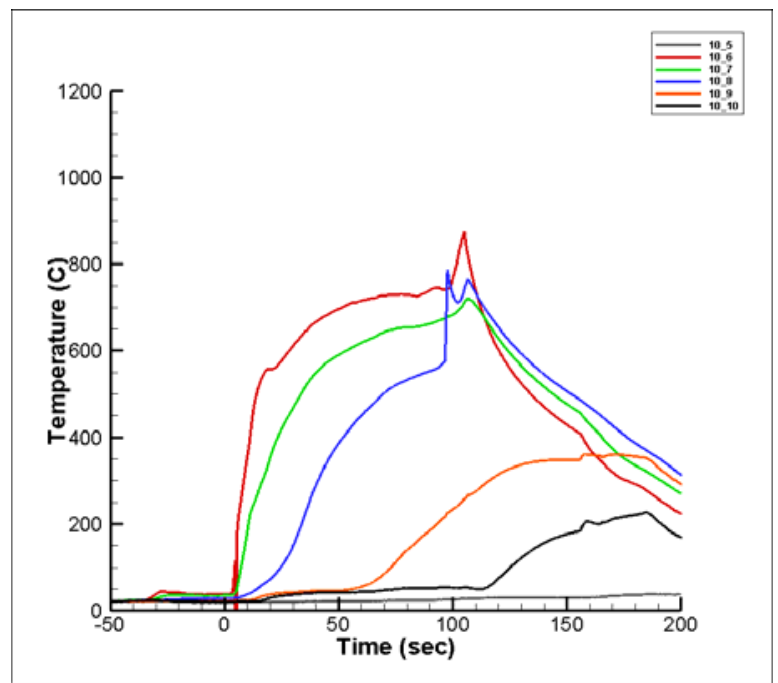

Figure 43. Run 10, Location 11, Layup 11, thermocouple data.

American Institute of Aeronautics and Astronautics 
performance. Sample location 4 survived the full duration of the run, but with a minor burn through of the 1554 top fabric at the center of the aft edge of the sample. The fact that these samples were not subjected to multiple tunnel aborts prior to testing was likely a contributing factor to their success. Figure 45 shows the PAIDAE sled test surface post-run. This picture captures the degraded state of the $\mathrm{SiO}_{2}$ test surfaces at the end of the test series.

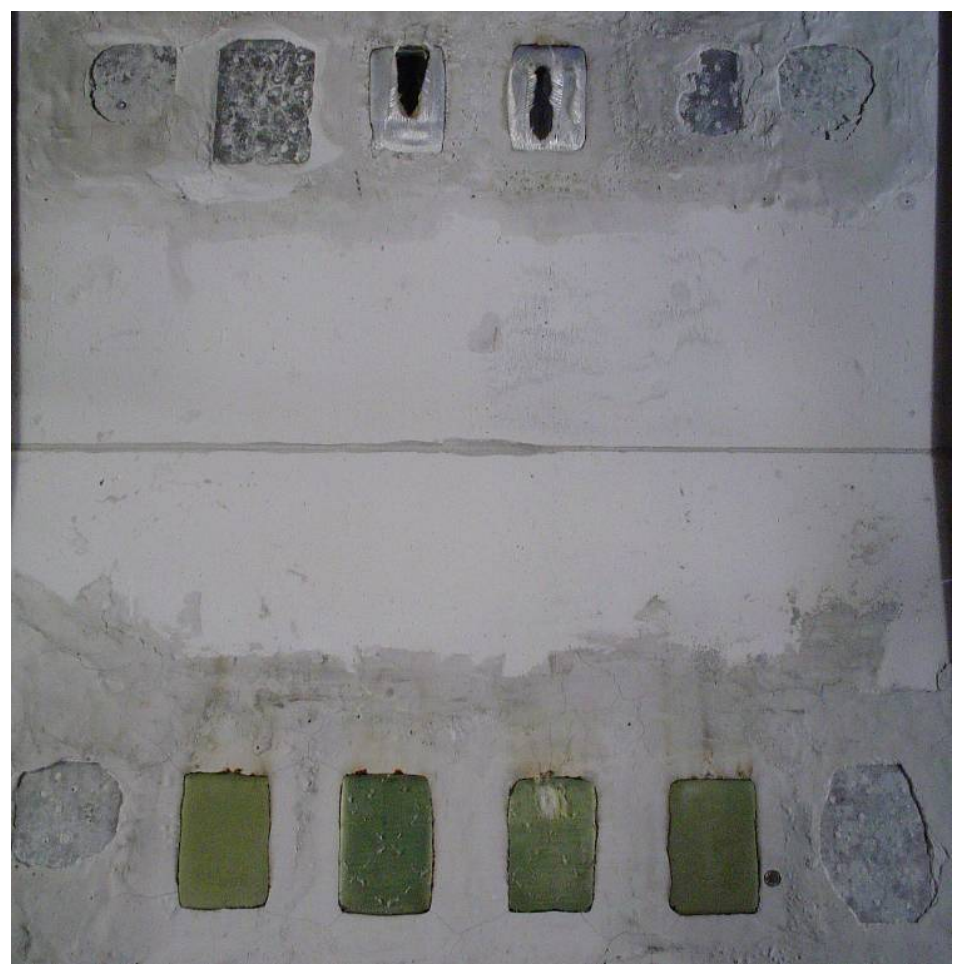

Figure 44. PAIDAE sled test surface post-test series.

\section{Conclusions}

The $\mathrm{SiO}_{2}$ foam was too delicate a material for the test surface in the PAIDAE test environment. Previous testing on the sled in 8Ft HTT had used this material, but we concluded that there might have been a formulation change as it did not perform as it had previously. Archived material from previous tests felt and appeared more substantial than the material used on the current test surfaces. Deterioration of the test surface during the runs caused unknown heating augmentation from flow disturbances. Eroding test surface material also impacted the inclined test surface causing unknown damage to samples in the aft location.

There was insufficient instrumentation on the sled test fixture. Pressure taps did an acceptable job indicating that the CFD was reasonably close predicting the environment to which the samples were exposed, but direct measurement of the flux applied would have been better. Thermal flux gages were not used on the test surface because none were found that could survive the very high surface temperatures expected, using the highly insulating $\mathrm{SiO}_{2}$ foam without actively cooling the detector body. Even if they had been incorporated, the gages would likely have been compromised by the material eroding off the test surface leaving them expensive surface plugs. Future tests are planned using a different test surface with significantly lower peak test surface temperatures allowing the use of passively cooled thermal flux gages. Additional cameras should have been incorporated to get a better view of the samples prior to sled injection. The camera locations for this test, looking down through the test section at the retracted sled, could often not image the samples after tunnel startup prior to sled injection, because of condensation in the test flow obscuring the samples. Condensation is a normal byproduct of the combustion process to produce the flow field, but appears to vary in concentration depending on ambient conditions on the day of testing.

BF20 appears to be the most durable of the off-the-shelf outer fabric candidates. It is heavier than both the AF14 and XN513, 3M Nextel products, which could contribute to the material's success. It is a readily available material and constructed with a desirable weave design.

UC100-28 showed promise, particularly given the low fabric areal weight. Unfortunately, there were not many tests run with the material. It might be a good candidate for a second fabric ply, perhaps behind a BF20 ply. 
1554-48 did survive many tests, but did not perform any better than BF20 which has half the areal weight. This material should likely be eliminated as a candidate for further testing.

Uncoated carbon fabric is unacceptable even in the low pressure at which the samples are tested. Enough oxygen is present in the flow to cause the fabric to flash. Silicon carbide cloth could be a candidate as it will not burn even in an oxidizing environment. This assumes the proper weave can be found or produced with adequate strength at temperature, low enough permeability, and adequate fabric flexibility and toughness to survive handling and high density packing.

Pyrogel3350 is an excellent candidate for the insulating material. It survives significantly higher temperatures than advertised and insulates better than the advertised conductivity. It is available in $1 / 8^{\text {th }}$ inch material thickness which is thin enough to allow tailoring layup thickness. Also, because multiple plies can be used, the seams can be offset preventing thermal leak paths at insulator seams.

Pyrogel6650 is an excellent insulator when the material remains intact, but the material is so susceptible to damage and difficult to handle it is not a good candidate insulator.

KFA5 carbon felt is a good insulator, although not quite as insulating as the Pyorgel3350 for equivalent mass. It does not sustain burning/charring when the heat is removed even in an oxidizing environment. It might be a good candidate for an insulator where higher temperature capability is required as long as enough outer fabric protects the insulator from the flow.

The Refrasil insulators (1800 and 2000) are not particularly good performers and are not very durable and will be removed as a candidate from future testing.

PAIDAE reports for each set of samples tested in the 8'HTT have been compiled in a project document ${ }^{4}$, and include a complete list of each layup, location, materials, runs, thermal and test results, as well as photographs of the pre- and post-test coupons, each material layer post test, and the notes generated by test engineers during the runs.

\section{Future Work}

Additional runs are going to be made in the 8ft HTT in the Spring/Summer of 2009 with what is believed to be a better selection for a test surface. Solid 1.5in aluminum plates will be used as a heat sink in place of the 0.313in aluminum plates with an insulator applied. Initial thermal analysis indicates that the forward test surface will not exceed $135^{\circ} \mathrm{C}$ for a 100 sec high pressure $5^{\circ}$ AoA run, and the aft surface will not exceed $223^{\circ} \mathrm{C}$. These temperatures allow the use of Medtherm thermal flux gages that are often used in the facility for direct flux measurement. Some candidate layups from the first test will be repeated to provide direct comparison of results. All samples will be quilted and supported. A NASA TP is forthcoming for this initial test series and a second will likely be written for the spring 2009 test series as well. Finally alternate facilities are being investigated to test material candidates. Probable candidates include the ARC Panel Facility and the LHMEL facility.

\section{Acknowledgments}

S. J. Hughes thanks the PAIDAE 8Ft HTT Team (Dr. F. M. Cheatwood, Charles Player, Walt Bruce, Katlin Liles, Nathanael Miller, Paul Ferlemann, and Monica Hughes), the 8Ft HTT personnel (Stephen Harvin, Robert Kyle, Pete Toth, Jason, Ty, Greg Mekkes, Eddie Rhyne, Mark Spieres and Jim Curro) and the ILC team for their efforts to prepare and conduct the test series. Thanks also to the Rex Materials personnel and their efforts to manufacture and apply large monolithic $\mathrm{SiO}_{2}$ Foam insulators for the test plates.

\section{References}

\footnotetext{
${ }^{1}$ Harvin, S.F., Cabell, K.F., Mekkes, G.L., and Gallimore, S.D., “Test Capability Enhancements to the NASA Langley 8-Foot High Temperature Tunnel,” JANNAF, 2006.

2 Ferlemann, P.G. “Analysis of the Material Test Sled During Injection into the 8'HTT Test Flow”, Technical Note 05-523, TEAMS Contract NNL07AA00B, NASA Langley Research Center, October 29, 2008.

${ }^{3}$ Del Corso, J.A., Bruce, W.E., Liles, K.A., and Hughes, S.J., "Thermal Analysis and Testing of Candidate Materials for PAIDAE Inflatable Aeroshell,” AIAA, ADS Conference, May 2009.

${ }^{4}$ Player, Charles, "PAIDAE Thermal Protection System Testing Final Report - FY2008,” PAI-DAE-3.3-012, NASA Langley Research Center, 2008.
} 